\title{
Production Rate of SiO Gas from Industrial Quartz and Silicon
}

\author{
CAROLINE SINDLAND and MERETE TANGSTAD
}

The production rate of $\mathrm{SiO}$ gas from industrial quartz and silicon has been investigated by isothermal heat treatment experiments. Mixtures of silicon and different quartz samples have been heated to temperatures ranging from $1650{ }^{\circ} \mathrm{C}$ to $1950{ }^{\circ} \mathrm{C}$ and held for 30 to 120 minutes before cooling. The weight loss of each sample has been correlated to degree of reaction and a model for the reaction rate of $\mathrm{Si}+\mathrm{SiO}_{2}$ has been developed based on these values. Five different types of industrial quartz were used in the experiments. No significant difference was found in their reaction rate, even though there are large variations in impurity content, melting rate, decrepitation, and phase transformation rate of each sample. Further on, it is shown that the reaction rate of silicon mixed with various types of quartz can be described by an Arrhenius equation: $\mathrm{d} \alpha / \mathrm{d} t=k_{0} A \exp (-Q / R T)$. A reaction constant $\left(k_{0}\right)$ equal to $6.2510^{8} \mathrm{~g} \mathrm{~s}^{-1} \mathrm{~m}^{-2}$ and an activation energy $(Q)$ equal to $557 \mathrm{~kJ} \mathrm{~mol}^{-1}$ were obtained by linear regression. The degree of reaction $(\alpha)$ is shown to be increasing with available reaction area, temperature, and time.

https://doi.org/10.1007/s11663-021-02143-4

(C) The Author(s) 2021

\section{INTRODUCTION}

SILICON is produced in Norway by the use of submerged arch furnaces (SAF) with coal, charcoal, woodchips, quartz, and electricity as input and silicon, $\mathrm{CO}_{\mathrm{g}}$, and silica as output. Reduction of quartz to form silicon occurs in several intermediate steps and the process is thoroughly described in Production of High Silicon Alloys by Schei et al. ${ }^{[1]} \mathrm{A}$ high silicon yield is one of the main goals in silicon production and it is dependent on the amount of losses in form of $\mathrm{SiO}_{\mathrm{g}}$ escaping through the exhaust, $\mathrm{SiC}$ build up in the furnace, and silicon metal lost during tapping. The first one, the amount of $\mathrm{SiO}_{\mathrm{g}}$ escaping through the exhaust, is dependent on the amount of $\mathrm{SiO}_{\mathrm{g}}$ produced in a silicon furnace. Investigation of the $\mathrm{SiO}_{\mathrm{g}}$-producing reactions is hence one step towards a more controlled silicon yield.

There are two $\mathrm{SiO}_{\mathrm{g}}$ forming reactions within a silicon furnace: the reaction between silicon carbide and silica and the reaction between silicon and silica. The incomplete reduction of silica with carbon $\left(\mathrm{SiO}_{2}+\right.$ $\mathrm{C}=\mathrm{CO}+\mathrm{SiO})$ can be divided into two steps: formation of silicon carbide and reaction between silicon

CAROLINE SINDLAND and MERETE TANGSTAD are with the The Department of Materials Science and Engineering, Norwegian University of Science and Technology, 7491 Trondheim, Norway. Contact e-mail: merete.tangstad@ntnu.no

Manuscript submitted September 19, 2020; accepted March 4, 2021.

Article published online April 21, 2021. carbide and silica to form $\mathrm{SiO}$ gas. The last step, reaction between silica and silicon carbide, is shown to be the rate determining step and the overall reaction is therefore not considered in this article. ${ }^{[2]}$ The first reaction, the reaction between silica and silicon carbide, has been investigated by Tangstad et al., who developed a model for the reaction rate, including a reaction constant and activation energy. ${ }^{[3]}$ The other reaction has not been thoroughly investigated and no model for reaction rate has been found in the literature. The goal of this project is hence to investigate the reaction rate of silicon and silica mixtures, described by Eq. [1], and to develop a model describing the reaction rate as function of temperature, time, available reaction area, and quartz quality. This will make it possible to compare the two $\mathrm{SiO}_{\mathrm{g}}$-producing reactions and further on give a better understanding of total $\mathrm{SiO}_{\mathrm{g}}$ losses in a silicon furnace.

$$
\mathrm{SiO}_{2(\mathrm{~s}, 1)}+\mathrm{Si}_{(\mathrm{l})}=2 \mathrm{SiO}_{(\mathrm{g})}
$$

\section{A. Metallurgical Production of High-Silicon Alloys}

The silicon furnace is normally divided in two zones: a low-temperature upper zone with temperatures ranging from $1300{ }^{\circ} \mathrm{C}$ to $1900{ }^{\circ} \mathrm{C}$ and a hot lower zone close to $2000{ }^{\circ} \mathrm{C}$. Quartz and carbon materials are added to the top of a silicon furnace. Carbon will react in the low-temperature zone according to Eq. [2] and silicon and silica will be formed in the low-temperature zone from the condensation reaction given by the reverse of Eq. [1]. The inputs in the hot zone are therefore $\mathrm{SiO}_{2}, \mathrm{C}$, $\mathrm{SiC}$, and $\mathrm{Si}$. The main silicon-producing reaction is 
happening within the hot zone and is given by Eq. [3]. The source of $\mathrm{SiO}$ gas is reaction between silicon and silica as well as silica and silicon carbide, according to Eqs. [1] and [4]. The CO gas formed in the hot-temperature zone and any $\mathrm{SiO}$ that does not react according to Eq. [3] will rise to the low-temperature zone. Some of the rising $\mathrm{SiO}$ gas will condensate according to the reverse of Eq. [1], while the rest will rise further and oxidize before it leaves the furnace as $\mathrm{SiO}_{2}$ in the exhaust system. The silica can be collected from the off gas and sold as a valuable product, but the goal is to control the amount of silica in the off gas, regardless of its value.

$$
\begin{gathered}
\mathrm{SiO}_{(\mathrm{g})}+2 \mathrm{C}_{(\mathrm{s})}=\mathrm{SiC}_{(\mathrm{s})}+\mathrm{CO}_{(\mathrm{g})} \\
\mathrm{SiC}_{(\mathrm{s})}+\mathrm{SiO}_{(\mathrm{g})}=2 \mathrm{Si}_{(\mathrm{l})}+\mathrm{CO}_{(\mathrm{g})} \\
2 \mathrm{SiO}_{2(\mathrm{~s}, \mathrm{l})}+\mathrm{SiC}_{(\mathrm{s})}=3 \mathrm{SiO}_{(\mathrm{g})}+\mathrm{CO}_{(\mathrm{g})}
\end{gathered}
$$

\section{B. Thermodynamics of the Si-O-C System}

There are multiple possible reactions in a $\mathrm{Si}-\mathrm{O}-\mathrm{C}$ system. The stability of reactions including $\mathrm{SiO}_{\mathrm{g}}$ is plotted as function of temperature and $\mathrm{SiO}$ pressure in Figure 1, where the total pressure of the system is assumed to be 1 bar $=P_{\mathrm{SiO}}+P_{\mathrm{CO}}$. Silicon and silica react to form $\mathrm{SiO}$ gas at $\mathrm{SiO}$ pressures below 0.1 bar when the temperature is $1600{ }^{\circ} \mathrm{C}$, at pressures below 0.6 bar when the temperature is $1800{ }^{\circ} \mathrm{C}$ and at any pressure when temperature is increased above $1850^{\circ} \mathrm{C}$. The standard Gibbs free energy for the reactions (given in $\mathrm{kJ}$ ) is listed in Table I for temperatures ranging from 1400 to $2000{ }^{\circ} \mathrm{C}$.

\section{The Reaction Rate of Silicon and Silica}

The rate of reaction between silicon and silica in pellets, described by Eq. [1], increases from $1550{ }^{\circ} \mathrm{C}$ to its maximum at $1850^{\circ} \mathrm{C}$, according to Bao et al. ${ }^{[4]}$ The reaction rate decreases at higher temperatures and two possible reasons are given: the reaction between silica and silicon is exothermic and the $\mathrm{Si}$ vapor increases at higher temperatures, leaving a very low reaction area between $\mathrm{SiO}_{2}$ and $\mathrm{Si}$. The reaction rate of silicon/silica pellets was calculated to be higher than the one of silica/SiC pellets at temperatures below $1820^{\circ} \mathrm{C}$ and the opposite was measured for temperatures above $1820^{\circ} \mathrm{C}$. The difference at high temperatures was assumed to be due to a low silicon/ silica reaction rate.

Andersen reported an exponential increase of reaction rate from $1450{ }^{\circ} \mathrm{C}$ to $1723^{\circ} \mathrm{C}$, a reduced reaction rate from $1723{ }^{\circ} \mathrm{C}$ to $1860{ }^{\circ} \mathrm{C}$ and finally a significant increase of reaction rate at $1910{ }^{\circ} \mathrm{C} .{ }^{[5]}$ Formation of bubbles at the silicon/silica interface was observed during heating of silicon and silica pellets between $1750{ }^{\circ} \mathrm{C}$ and $1869{ }^{\circ} \mathrm{C}$ in a wettability furnace, indicating formation of $\mathrm{SiO}$ gas. The drop in reaction rate at these temperatures was therefore related to a high viscosity of the liquid silica and a low gas removal rate. The equilibrium pressure of $\mathrm{SiO}$ gas exceeds 1 bar around $1860{ }^{\circ} \mathrm{C}$ and this is pointed out as a possible reason for

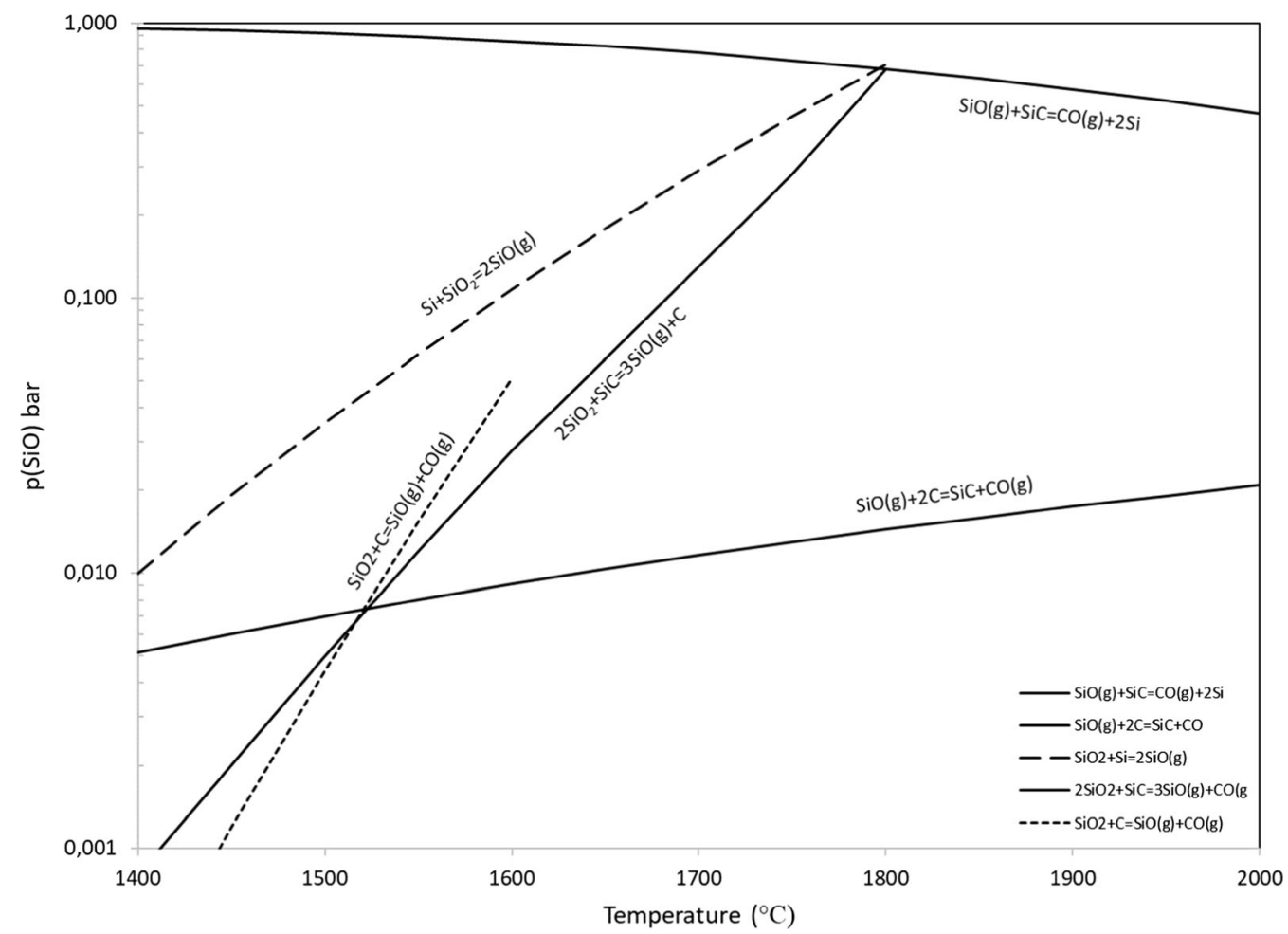

Fig. 1-Equilibrium pressure of reactions within the Si-C-O system, calculated by the use of HSC Chemistry 9. 


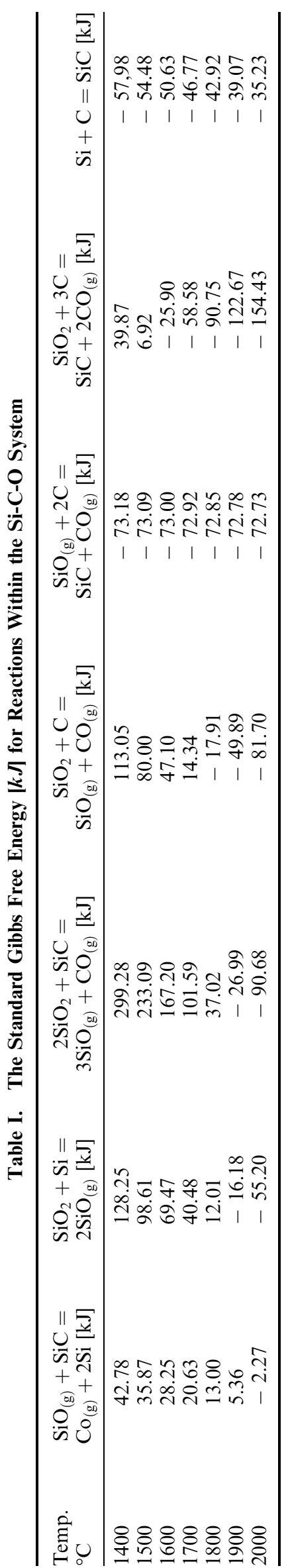

Table II. Reaction Constant and Activation Energy for $2 \mathrm{SiO}_{-} 2+\mathrm{SiC}=3 \mathrm{SiO}+\mathrm{CO}$, Measured in Pellets. ${ }^{|3|} \boldsymbol{k}_{\mathbf{0}}$ is

Given for the Case Where the Surface Area of $\mathrm{SiO}_{2}$ is Limiting

\begin{tabular}{lc}
\hline$k_{0}\left[\mathrm{~g} \mathrm{~s}^{-1} \mathrm{~cm}^{-2}\right]$ & $\mathrm{Q}\left[\mathrm{kJ} \mathrm{mol}^{-1}\right]$ \\
\hline $1.9 \times 10^{5}$ & $424-464$ \\
\hline
\end{tabular}

the increasing reaction rate at high temperatures. An activation energy between $438 \mathrm{~kJ} /$ mole and $528 \mathrm{~kJ} / \mathrm{mole}$ is reported by Andersen. ${ }^{[5]}$

\section{Reaction Rate of Silica and Silicon Carbide}

The second reaction producing $\mathrm{SiO}$ gas in the silicon furnace (in addition to $\mathrm{Si} / \mathrm{SiO}_{2}$ reaction) is described by Reaction 4 where $\mathrm{SiO}_{2}$ reacts with $\mathrm{SiC}$ to $\mathrm{SiO}$ and $\mathrm{CO}$ gas. The reaction rate of the reaction between $\mathrm{SiC}$ and silica has been measured by Tangstad et al., describing the rate by Eq. [5], under the assumption that the surface area of $\mathrm{SiO}_{2}$ is rate limiting. ${ }^{[3]}$ Their obtained values for reaction constant and activation energy are presented in Table II. The measurements were done on pellets which give a high reaction area compared to experiments with particles. They did not find any significant difference between pellets of quartz and $\mathrm{SiC}$ compared to pellets of cristobalite and $\mathrm{SiC}$.

$$
\frac{\mathrm{d} \alpha}{\mathrm{d} t}=k_{0} A_{0}(1-\alpha) \exp \left(\frac{-Q}{\mathrm{RT}}\right),
$$

where $\alpha$ is the degree of reaction [ ], $t$ is the time [s], $k_{0}$ is the reaction constant $\left[\mathrm{g} \mathrm{s}^{-1} \mathrm{~cm}^{-2}\right], A_{0}$ is the initial reaction $\operatorname{area}\left[\mathrm{cm}^{2} \mathrm{~g}^{-1}\right], \quad Q$ is the activation energy $\left[\mathrm{Jmol}^{-1}\right], R\left[\mathrm{~mol} \mathrm{~J}^{-1} \mathrm{~K}^{-1}\right]$ is the gas constant, and $T$ is the temperature $[\mathrm{K}]$.

The reaction rate of silica and silicon carbide pellets has also been investigated by Bao et al. at an earlier stage. ${ }^{[4]}$ They heated pellets of silica and silicon carbide to 1550,1730 , and $1820^{\circ} \mathrm{C}$ at a heating rate of $15^{\circ} \mathrm{C} /$ min and held it for a given time. They found that the reaction rate is almost constant at $1550{ }^{\circ} \mathrm{C}$ and then increases exponentially to $1820^{\circ} \mathrm{C}$, until the samples are almost completely consumed. Temperature accelerates the reaction substantially. Andersen found that the reaction rate increases exponentially from $1450{ }^{\circ} \mathrm{C}$ to about $1700{ }^{\circ} \mathrm{C}$; it had a constant or reduced rate during melting and a rapid increase from $1770{ }^{\circ} \mathrm{C} .^{[5]}$

\section{E. Quartz}

Quartz goes through multiple phase transitions when heated from room temperature to $1800{ }^{\circ} \mathrm{C}$. The stable phase at room temperature is $\alpha$ - quartz which will transform into $\beta$ - quartz at $573{ }^{\circ} \mathrm{C}$. Transition into HP-tridymite occurs at $870{ }^{\circ} \mathrm{C}$ before it is transformed into $\beta$ - cristobalite at $1470{ }^{\circ} \mathrm{C}$ and melting occurs at $1728^{\circ} \mathrm{C}$, according to Manual of Mineralogy. $\left({ }^{[6]}\right.$, p. 530) Melting occurs at $1713^{\circ} \mathrm{C}$ according to SI-chemical data. ${ }^{[7]}$ The transformation to tridymite as described in Manual of Mineralogy is debated in several other publications. ${ }^{\left[{ }^{[-10]}\right.}$ It is shown that tridymite is an impurity-derived structure 
and not stable in pure silica. Transition from quartz to cristobalite seems to occur via a non-crystalline transition phase and can be described by Reaction 6 .

$$
\text { Quartz } \rightarrow \text { Amorphousphase } \rightarrow \text { cristobalite }
$$

Phase transformation in different industrial quartz samples has been investigated by Jusnes and among them are the samples labeled quartz B, C, and D, later discussed in this article. ${ }^{[9]}$ There is a significant difference in their transformation rate. The phase compositions of quartz B, C, and D after they have been heated to $1650{ }^{\circ} \mathrm{C}$ and held for 0,30 , and 60 minutes are presented in Figure 2. Quartz B has a higher rate of transformation than quartz $\mathrm{C}$ which again has a higher rate than quartz D.

Melting and decrepitation of silica have been investigated by Nordnes and Jusnes et al., and both properties seem to vary significant between different types of industrial quartz. ${ }^{[11,12]} \mathrm{A}$ low amount of particles below $10 \mathrm{~mm}(<5 \mathrm{pct})$ was found after shock heating of quartz $\mathrm{C}$, while the amount of particles below $10 \mathrm{~mm}$ was about 30 pet for quartz $B$ and about 75 pct for quartz D. There is also a significant difference in the melting rate of quartz $\mathrm{B}$ and $\mathrm{C}$ but no information has been obtained for the other samples used in this article. A summary of values obtained for melting and decrepitation of the quartz samples used in this article can be found in Figure 3.

\section{F. Wettability in the Si-O-C System}

Silicon on graphite has an initial contact angle of about $120{ }^{\circ} \mathrm{C}$, but liquid silicon will eventually wet the substrate due to formation of a $\mathrm{SiC}$ layer at the interface. The equilibrium contact angle of silicon on a graphite substrate is reported to be 3 to $40{ }^{\circ} \mathrm{C}$ by Ciftja et al and Dezellus et al ${ }^{[13,14]}$ The final angle is dependent on the surface roughness and is obtained after 5 to 10 min of heating. ${ }^{[13]}$

Silicon has a contact angle of $90 \mathrm{deg}$ on solid silica substrates. ${ }^{[15]}$ It has been observed that silicon droplets vibrate on silica substrates, resulting in an oscillating contact angle and further on spreading due to changes in the solid-liquid surface tension. An apparent average wetting angle between $90 \mathrm{deg}$ and $95 \mathrm{deg}$ is reported by other sources that also observed vibration of the silicon droplet where experiments were performed in $1 \mathrm{~atm} \mathrm{Ar}$ atmosphere. ${ }^{[16,17]}$ Formation and release of $\mathrm{SiO}_{\mathrm{g}}$ is a suggested cause of vibration and no secondary phase was found on the silicon/silica interface. Leakage paths like dimples and grooves are found to reduce the amount of vibration and a more constant wetting angle was observed in this case compared to heating on a smooth substrate. ${ }^{[16]}$

Heating of brown condensate in a sessile drop furnace has been performed by Vangskåsen. ${ }^{[18]}$ The condensate consisted mostly of silicon and silica, products from the condensation of $\mathrm{SiO}_{\mathrm{g}}$, represented by Reaction 1 reversed. The silicon in the brown condensate melted away from the surrounding $\mathrm{SiO}_{2}$ at temperatures above $1395^{\circ} \mathrm{C}$. The separation of silicon happened most rapidly above $1700{ }^{\circ} \mathrm{C}$. The remaining amorphous $\mathrm{SiO}_{2}$ retained its shape up to the maximum temperature of the furnace at about $1850{ }^{\circ} \mathrm{C}$ and showed no signs of melting. Silicon and silica did not wet each other.

Images from melting and softening experiments performed with silica on a graphite substrate in a sessile drop furnace show a contact angle above $90 \mathrm{deg}$, meaning that the silica does not wet the graphite substrate. ${ }^{[11]}$

Boron nitride $(\mathrm{BN})$ is one of the very few materials that is non-wetted by liquid silicon. The contact angle between the two materials has been reported to be between 105 and $145 \mathrm{deg}$, all within the non-wetting area. $^{[19-21]}$

\section{EXPERIMENTAL}

The reaction rate of five different quartz samples mixed with one type of metallurgical grade silicon has been investigated. Isothermal heat treatment of $1: 1$ molar mixtures of silicon and silica in graphite crucibles has been performed, to measure the weight loss after experiment as function of time and temperature, which have been correlated to reaction rate. A total of 30 experiments have been performed at temperatures between $1650{ }^{\circ} \mathrm{C}$ and $1950{ }^{\circ} \mathrm{C}$, with holding times between 30 and 120 minutes and a heating rate of $50 \mathrm{~K} / \mathrm{min}$ until isothermal temperature was reached. 17 of the experiments were performed with one type of quartz (quartz A) mixed with silicon of metallurgical grade, while another 13 experiments have been performed with four different industrial quartz samples (B to E), to investigate the effect of quartz type on the reaction rate of silicon and silica. Different size fractions of quartz $\mathrm{E}$ were heated, to investigate the effect of size fraction on the reaction rate. Both mixing and layering of the raw materials (with silicon on top of silica) were tested for experiments with quartz A. Mixing of the raw materials was the chosen method for the rest of the experiments. The chemical composition of the silicon was similar in all experiments but the size fraction of the silicon was equal to the size fraction of the quartz used in each experiment. Chemical composition and particle size of the silicon and quartz used in the experiments are presented in Tables III and IV, respectively. A list of all of the experiments, including quartz sample, size fraction, mixing/layering of raw materials, time, and temperature can be found in Table V.

A total of $20 \mathrm{~g}$ silicon and silica (1:1 molar ratio) was heated in high-density graphite crucibles, except experiment 5 where a h-BN crucible was used. 24 of the samples were heated in a resistance heat furnace, while 6 of the samples (experiment number 3, 4, 9, 10, 12, and 15) were heated in an induction heat furnace. All of the samples were inserted in a reaction chamber made of graphite, closed by a condensation chamber filled with $\mathrm{SiC}$ particles, as seen in Figure 4. A temperature gradient in the system causes any formed $\mathrm{SiO}$ gas that rises to condense on the $\mathrm{SiC}$ particles before the gas escape through the exhaust system of the furnace. The reaction chamber was vacuumed before it was filled with 


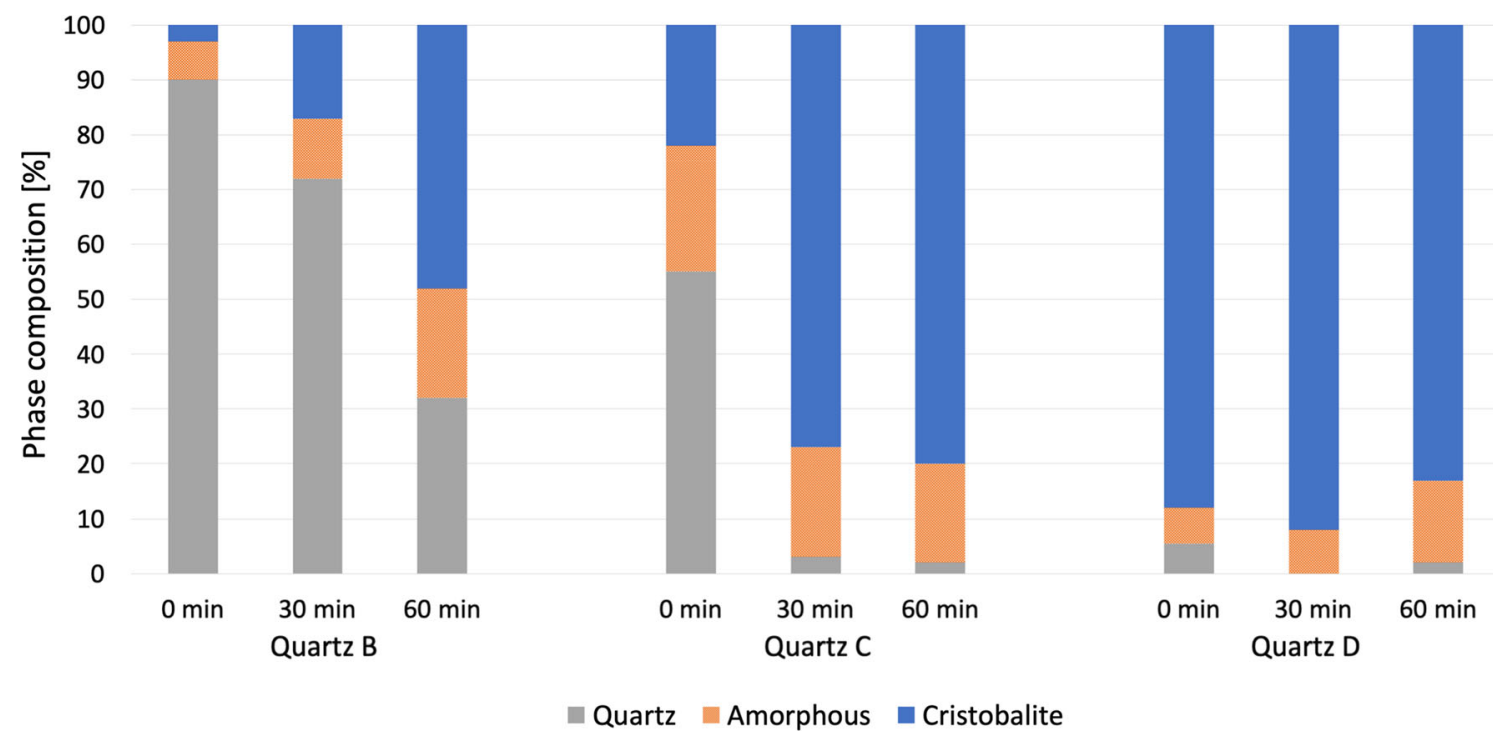

Fig. 2-Phase transformation in quartz B, C, and D after heating to $1600{ }^{\circ} \mathrm{C}$ for 0 , 30, and 60 min obtained from work done by Jusnes. ${ }^{[9]}$

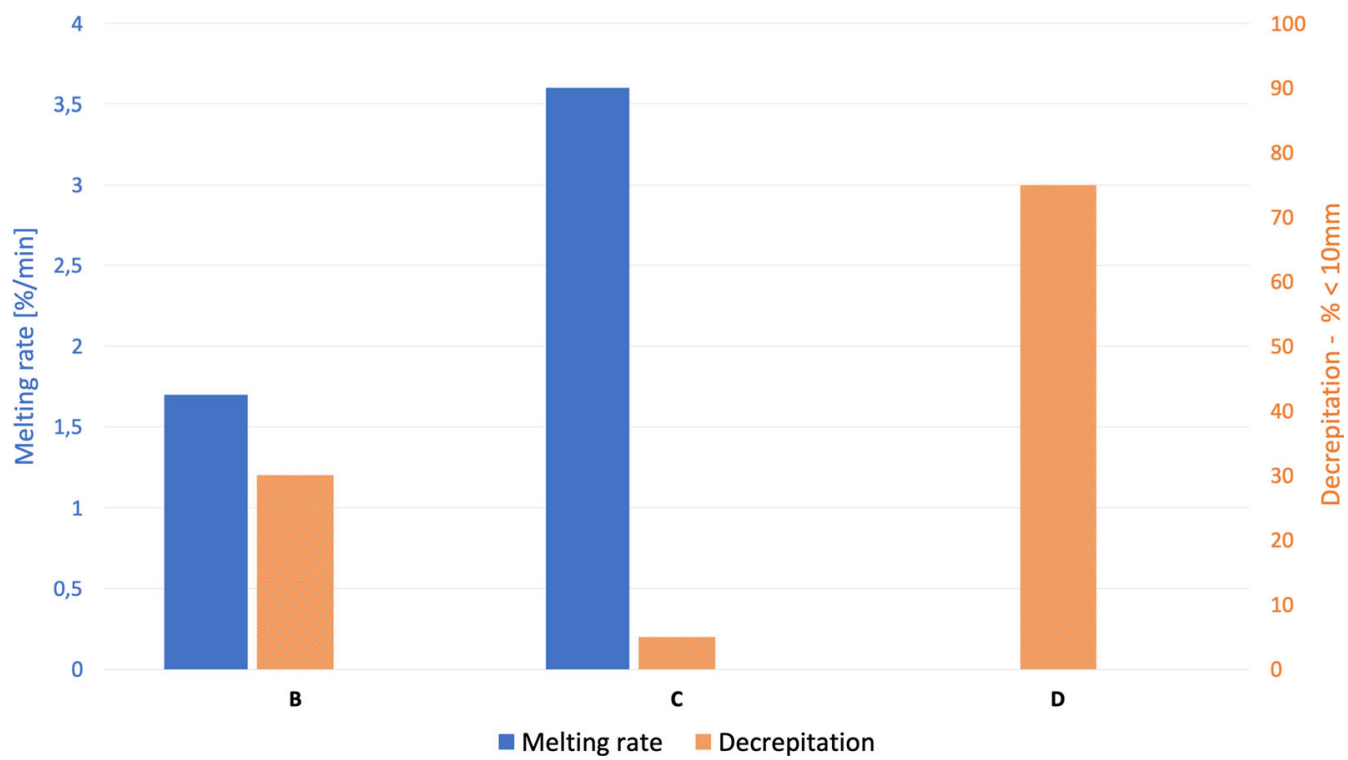

Fig. 3- Melting rate of quartz $\mathrm{B}$ and $\mathrm{C}$ at $1750{ }^{\circ} \mathrm{C}$ obtained from work done by Nordnes. ${ }^{[11]}$ Decrepitation of quartz B, C, and D after shock heating to $1500{ }^{\circ} \mathrm{C}$ obtained from work done by Jusnes, given as percentage of particles that are below $10 \mathrm{~mm} .{ }^{[12]}$

argon (99.999 pct) and heating started once a pressure of 1.5 bar was reached. A constant pressure of 1.5 bar was maintained by a flow of argon entering the top of the reaction chamber. The temperature was monitored by a C-type thermocouple covered by graphite, placed in the center of the sample crucible. The weight of the crucible was measured with and without sample before heating and with sample after heating, giving the total weight loss relatively to initial sample weight, described by Eq. [7].

$\mathrm{Wt}$. loss $=\frac{(\text { crucible, sample and } \text { cover })_{\text {before }}-(\text { crucible, sample and cover })_{\text {after }}}{\text { sample weight before }}$.
Wettability of silicon on silica was measured in a sessile drop furnace by heating of silicon on a substrate of different quartz samples in argon atmosphere, while images of the sample is taken thought the entire experiment. All of the samples were heated in the same furnace (furnace 1) except one parallel (with quartz $\mathrm{C}$ as substrate) that was heated in furnace 2 . It would have been preferred to run multiple parallels in both furnaces but this was not possible due to technical problems with furnace 2 . The images were analyzed and a wetting angle was obtained for each sample by the use of ImageJ. Substrates of quartz B to $\mathrm{E}$ were made by cutting and grinding of discs from core samples (a core sample of quartz A was not 
Table III. Composition and Size Fraction of the Silicon

\begin{tabular}{|c|c|c|c|c|c|}
\hline Particle size (mm) & Si (Weight Percent) & Fe (Weight Percent) & Ca (Weight Percent) & $\mathrm{Ti}(\mathrm{ppmw})$ & $\mathrm{P}(\mathrm{ppmw})$ \\
\hline 1 to 2,2 to 5 and 5 to 8 & $\min 99.0$ & $\max 0.40$ & $\max 0.10$ & 200 to 300 & 20 to 40 \\
\hline
\end{tabular}

Table IV. Composition and Size Fraction of the Quartz. Sample A was Analyzed by ICP-OES, While B to E was Analyzed by XRF. The Rest of the Sample is Assumed to be $\mathrm{SiO}_{2}$

\begin{tabular}{|c|c|c|c|c|c|c|c|c|c|}
\hline Name & Particle size $(\mathrm{mm})$ & $\begin{array}{c}\mathrm{Al} \\
\text { (Weight } \\
\text { Percent) }\end{array}$ & $\begin{array}{c}\mathrm{Fe} \\
\text { (Weight } \\
\text { Percent) }\end{array}$ & $\begin{array}{c}\text { K } \\
\text { (Weight } \\
\text { Percent) }\end{array}$ & $\begin{array}{c}\mathrm{Ca} \\
\text { (Weight } \\
\text { Percent) }\end{array}$ & $\begin{array}{c}\text { Ti } \\
\text { (Weight } \\
\text { Percent) }\end{array}$ & $\begin{array}{c}\text { Mg } \\
\text { (Weight } \\
\text { Percent) }\end{array}$ & $\begin{array}{c}\mathrm{Na} \\
\text { (Weight } \\
\text { Percent) }\end{array}$ & $\begin{array}{c}\text { P } \\
\text { (Weight } \\
\text { Percent) }\end{array}$ \\
\hline A & 2 to 5 & 0.031 & 0.012 & 0.009 & 0.0046 & 0.002 & 0.0017 & 0.001 & 0.0003 \\
\hline $\mathrm{B}$ & 1 to 2 & 0.006 & 0.006 & 0.002 & $<0.0011$ & $<0.001$ & 0.0005 & $<0.0011$ & $<0.0004$ \\
\hline $\mathrm{C}$ & 1 to 2 & 0.211 & 0.192 & 0.063 & 0.0026 & 0.017 & $<0.0005$ & 0.0022 & 0.0016 \\
\hline $\mathrm{D}$ & 1 to 2 & 0.038 & 0.010 & 0.017 & 0.0415 & 0.001 & $<0.0005$ & 0.0125 & $<0.0004$ \\
\hline $\mathrm{E}$ & 1 to 2,2 to 5 and 5 to 8 & 0.505 & 0.111 & 0.126 & 0.0324 & 0.016 & 0.0071 & $0.027 *$ & 0.0016 \\
\hline
\end{tabular}

Table V. Experiment Number, Quartz Type, Fraction, Temperature, Whether the Raw Materials Were Mixed or Layered, and Holding Time for Each Experiment are Listed as Well as sample Weight Loss After Heating

\begin{tabular}{|c|c|c|c|c|c|c|}
\hline Exp. $\mathrm{Nr}$ & Quartz & Frac. $[\mathrm{mm}]$ & $\mathrm{T}\left[{ }^{\circ} \mathrm{C}\right]$ & $\mathrm{t}_{\text {hold }}[\mathrm{min}]$ & Weight Loss [Weight Percent] & Raw Materials \\
\hline 1 & blank & - & 1800 & 60 & $\sim 0$ & - \\
\hline 2 & A & 2 to 5 & 1670 & 120 & 3.25 & mixed \\
\hline 3 & A & 2 to 5 & 1655 & 120 & 2.50 & layered \\
\hline 4 & A & 2 to 5 & 1750 & 60 & 3.49 & layered \\
\hline 5 & A & 2 to 5 & 1750 & 60 & 4.40 & layered \\
\hline 6 & A & 2 to 5 & 1775 & 120 & 12.65 & mixed \\
\hline 7 & A & 2 to 5 & 1756 & 120 & 7.31 & layered \\
\hline 8 & A & 2 to 5 & 1751 & 120 & 9.25 & mixed \\
\hline 9 & A & 2 to 5 & 1750 & 180 & 8.95 & layered \\
\hline 10 & A & 2 to 5 & 1850 & 30 & 9.08 & layered \\
\hline 11 & A & 2 to 5 & 1880 & 60 & 22.00 & mixed \\
\hline 12 & A & 2 to 5 & 1850 & 60 & 19.35 & layered \\
\hline 13 & A & 2 to 5 & 1856 & 60 & 13.81 & layered \\
\hline 14 & A & 2 to 5 & 1854 & 60 & 16.52 & mixed \\
\hline 15 & A & 2 to 5 & 1850 & 120 & 32.10 & layered \\
\hline 16 & A & 2 to 5 & 1932 & 30 & 46.63 & mixed \\
\hline 17 & A & 2 to 5 & 1985 & 60 & 71.80 & mixed \\
\hline 18 & A & 2 to 5 & 1959 & 60 & 55.52 & mixed \\
\hline 19 & $\mathrm{~B}$ & 1 to 2 & 1650 & 120 & 4.40 & mixed \\
\hline 20 & B & 1 to 2 & 1850 & 60 & 20.56 & mixed \\
\hline 21 & $\mathrm{C}$ & 1 to 2 & 1650 & 120 & 5.10 & mixed \\
\hline 22 & $\mathrm{C}$ & 1 to 2 & 1750 & 120 & 11.83 & mixed \\
\hline 23 & $\mathrm{C}$ & 1 to 2 & 1850 & 60 & 26.45 & mixed \\
\hline 24 & $\mathrm{C}$ & 1 to 2 & 1950 & 30 & 47.35 & mixed \\
\hline 25 & $\mathrm{D}$ & 1 to 2 & 1650 & 120 & 5.66 & mixed \\
\hline 26 & $\mathrm{D}$ & 1 to 2 & 1850 & 60 & 23.20 & mixed \\
\hline 27 & $\mathrm{E}$ & 1 to 2 & 1650 & 120 & 4.45 & mixed \\
\hline 28 & $\mathrm{E}$ & 1 to 2 & 1850 & 60 & 22.57 & mixed \\
\hline 29 & $\mathrm{E}$ & 2 to 5 & 1850 & 60 & 17.85 & mixed \\
\hline 30 & $\mathrm{E}$ & 5 to 8 & 1650 & 120 & 2.60 & mixed \\
\hline 31 & $\mathrm{E}$ & 5 to 8 & 1850 & 60 & 13.54 & mixed \\
\hline
\end{tabular}

Each sample was weighted to $20.0 \mathrm{~g}$ prior to heating with a $\mathrm{Si}: \mathrm{SiO}_{2}$ molar ratio of 1:1 and heated in a graphite crucible except experiment 5 where a h-BN crucible was used. 


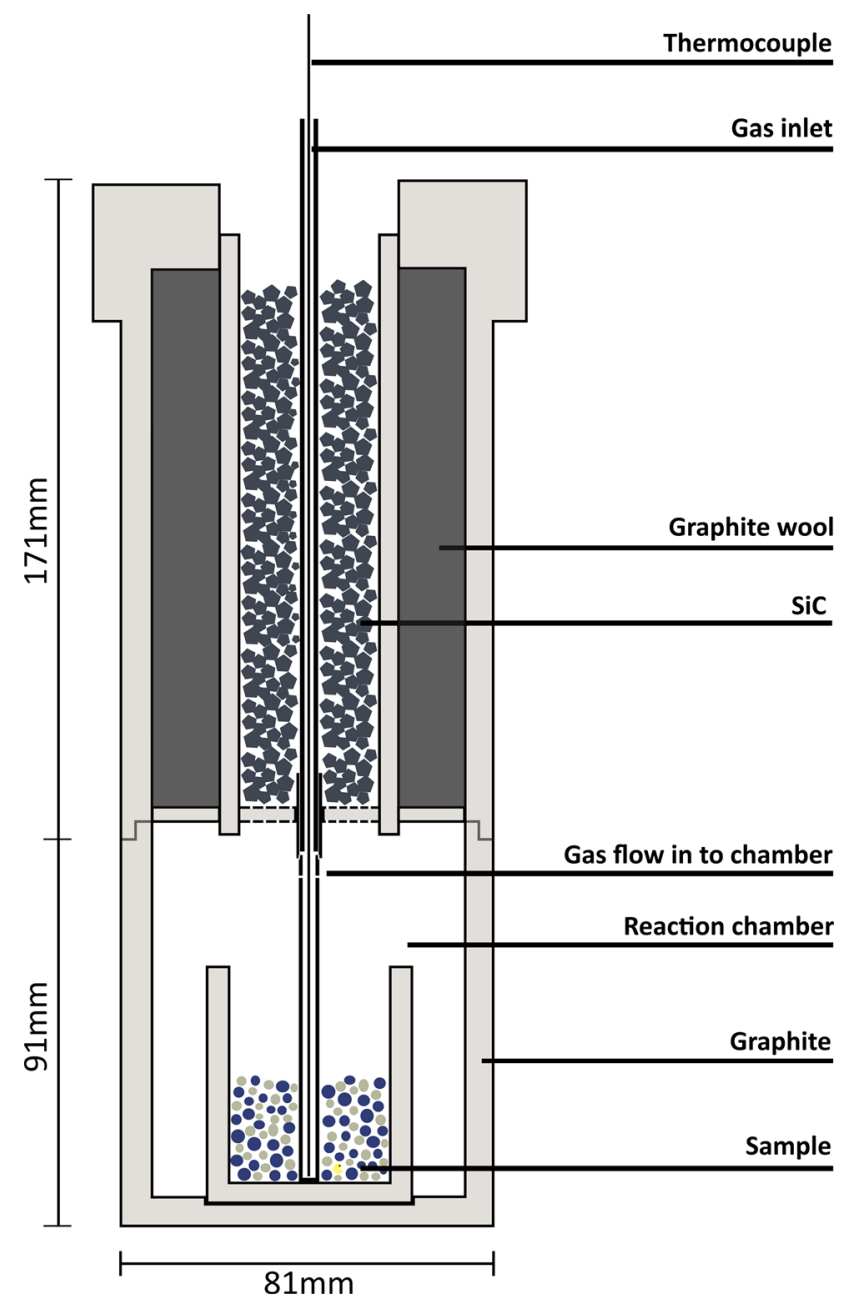

available and the wettability of this sample was therefore not tested). The sample was set to be heated to $900{ }^{\circ} \mathrm{C}$ within 3 minutes before it was heated to $1350{ }^{\circ} \mathrm{C}$ at a heating rate of $50 \mathrm{~K} / \mathrm{min}$ and finally at a rate of $5 \mathrm{~K} / \mathrm{min}$ to $1523{ }^{\circ} \mathrm{C}$. It was then set to be held at $1523{ }^{\circ} \mathrm{C}$ for 120 minutes before cooling. Pictures were taken throughout the entire experiment with 1 image per $\mathrm{K}$ ( 2 images per $\mathrm{K}$ during heating from $900{ }^{\circ} \mathrm{C}$ to $1450{ }^{\circ} \mathrm{C}$ ).

\section{RESULTS AND DISCUSSION}

Reaction rate of silicon and silica is both dependent on and increased by available reaction area, temperature, and time. This have been confirmed by 30 experiments where a mixture of silicon and different types of industrial quartz samples have been heated at temperatures ranging from $1650{ }^{\circ} \mathrm{C}$ to $1950^{\circ} \mathrm{C}$ and times varying from 30 to 120 minutes. The degree of reaction is calculated based on weight loss of each sample and no significant difference between the reaction rate of the different types of industrial quartz was found, which will be further discussed in Section "III-A". The phase distribution after heating of the samples has been investigated by macro and SEM images and the properties of the different quartz samples are discussed, based on chemical analysis, XRD, and information on each specific sample found in the literature. A comparison of the two SiO-producing reactions in a silicon furnace and their behavior as a function of temperature will be discussed in Section "III-E", based on the result of this report and literature on the silica/SiC reaction rate.

Fig. 4 -Experimental setup.

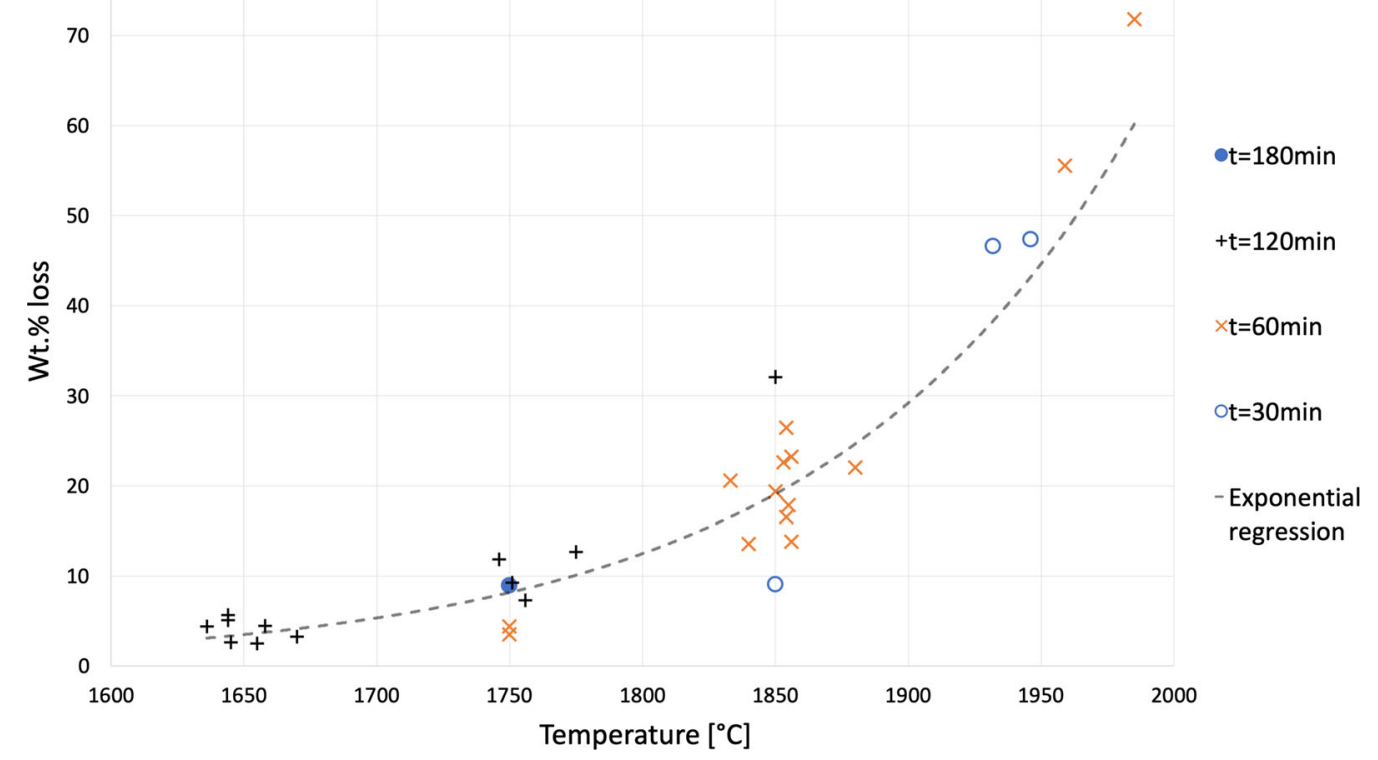

Fig. 5-The weight loss after heating samples of quartz A to E mixed with silicon. The dotted line is a regression (not the reaction rate model) based on all of the experimental data to indicate that weight loss increase with time and temperature. 
The weight loss of each sample is listed in Table $\mathrm{V}$ and plotted as function of temperature in Figure 5. The weight loss increases with time and temperature, as indicated by a regression based on the data in Figure 5. It is assumed that the weight loss of a sample can be directly correlated to the reaction rate and the weight loss is assumed to be due to $\mathrm{SiO}$ formation only. This

Table VI. Values for Reaction Constant and Activation Energy Obtained from a Linear Regression in the Arrhenius Plot in Fig. 6

\begin{tabular}{|c|c|}
\hline$k_{0}\left[\begin{array}{ll}\mathrm{g} & \left.\mathrm{s}^{-1} \mathrm{~m}^{-2}\right]\end{array}\right.$ & $\mathrm{Q}\left[\mathrm{kJ} \mathrm{mol}^{-1}\right]$ \\
\hline $6.2 \times 10^{8}$ & 557 \\
\hline
\end{tabular}

will be discussed and justified in Section "III-B" section. Based on that, the reaction rate of silicon and silica mixtures was found to follow an Arrhenius equation, described by Eqs. [8] through [11] (where $\alpha$ is the degree of reaction [ ], $t[\mathrm{~s}]$ is the time, $k_{0}$ is the reaction constant $\left[\mathrm{g} \mathrm{s}^{-1} \mathrm{~cm}^{-2}\right], A$ is the available reaction area $\left[\mathrm{cm}^{2} \mathrm{~g}^{-1}\right], A_{0, \mathrm{Si}}$ is the initial reaction area of silicon $\left[\mathrm{cm}^{2} \mathrm{~g}^{-1}\right], r_{0, \mathrm{Si}}$ is the initial radius of silicon particles, $F$ is the agglomeration factor, $Q$ is the activation energy $[\mathrm{J}]$, $\rho_{\mathrm{Si}}$ is the density of silicon, $S_{\text {part }}$ and $V_{\text {part }}$ are the surface and volume of one silicon particle). There is no significant difference between the reaction rate of the five different quartz types. Values for reaction constant $\left(k_{0}\right)$ and activation energy $(Q)$ are presented in Table VI. The values have been obtained from the linear regression in Figure 6, an Arrhenius plot of all 30 samples.

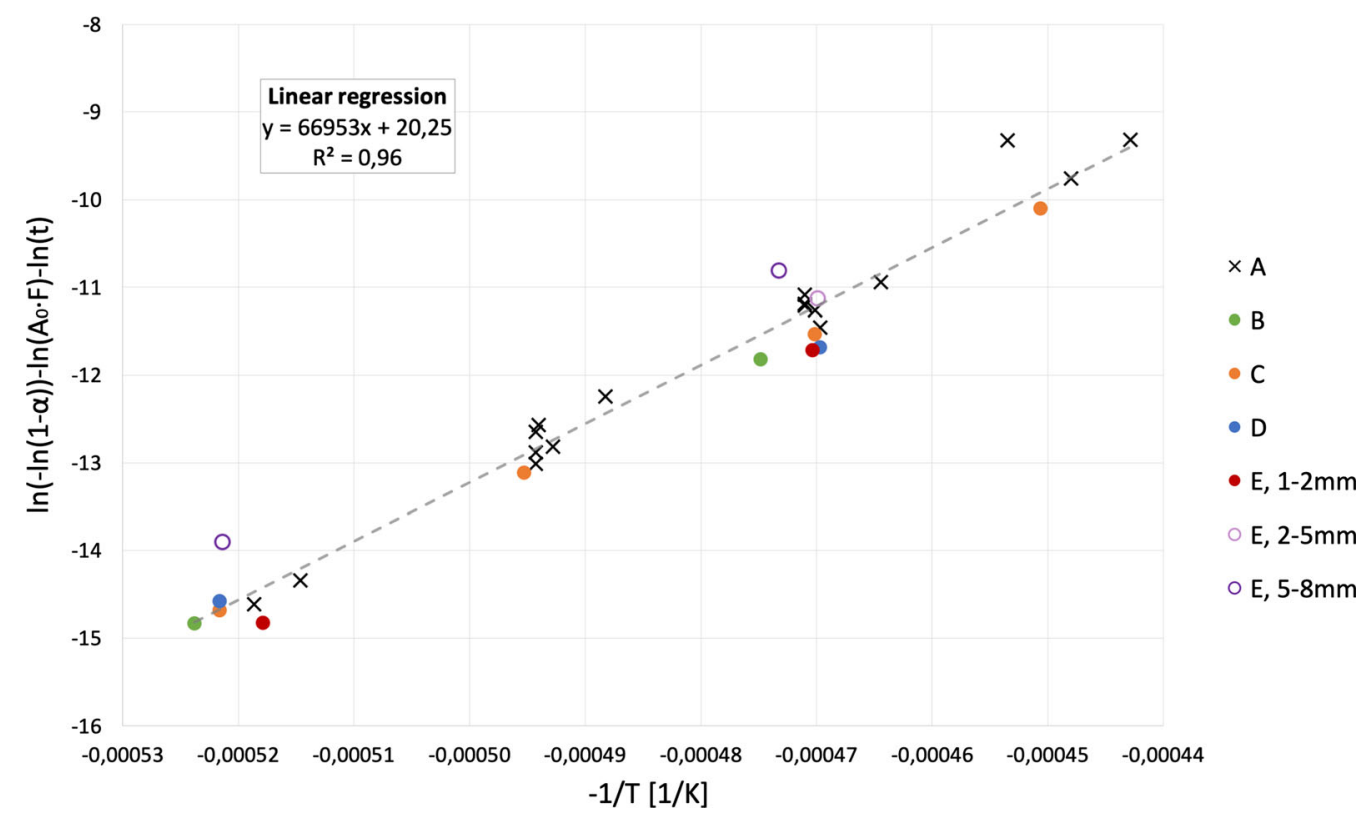

Fig. 6-An Arrhenius plot of the experimental data. The different shapes (and colors) indicate the different types of quartz and the fraction of the raw materials in the case where different fractions were used for the same type of quartz (Color figure online).
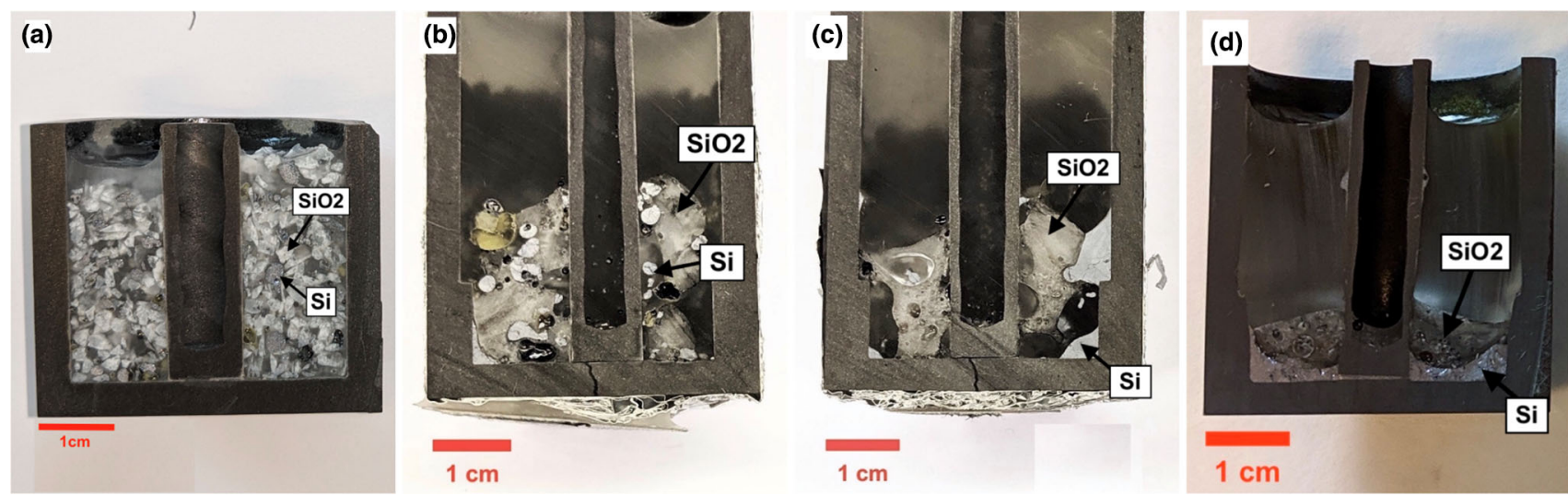

Fig. 7-The samples agglomerate as the degree of reaction $(\alpha)$ increase. (a) $1650{ }^{\circ} \mathrm{C}$ for $120 \mathrm{~min}, \alpha=0.04$. (b) $1750{ }^{\circ} \mathrm{C}$ for $120 \mathrm{~min}, \alpha=0.09$. $(c)$ $1850{ }^{\circ} \mathrm{C}$ for $60 \mathrm{~min}, \alpha=0.17$. (d) $1950{ }^{\circ} \mathrm{C}$ for $60 \mathrm{~min}, \alpha=0.56$. 


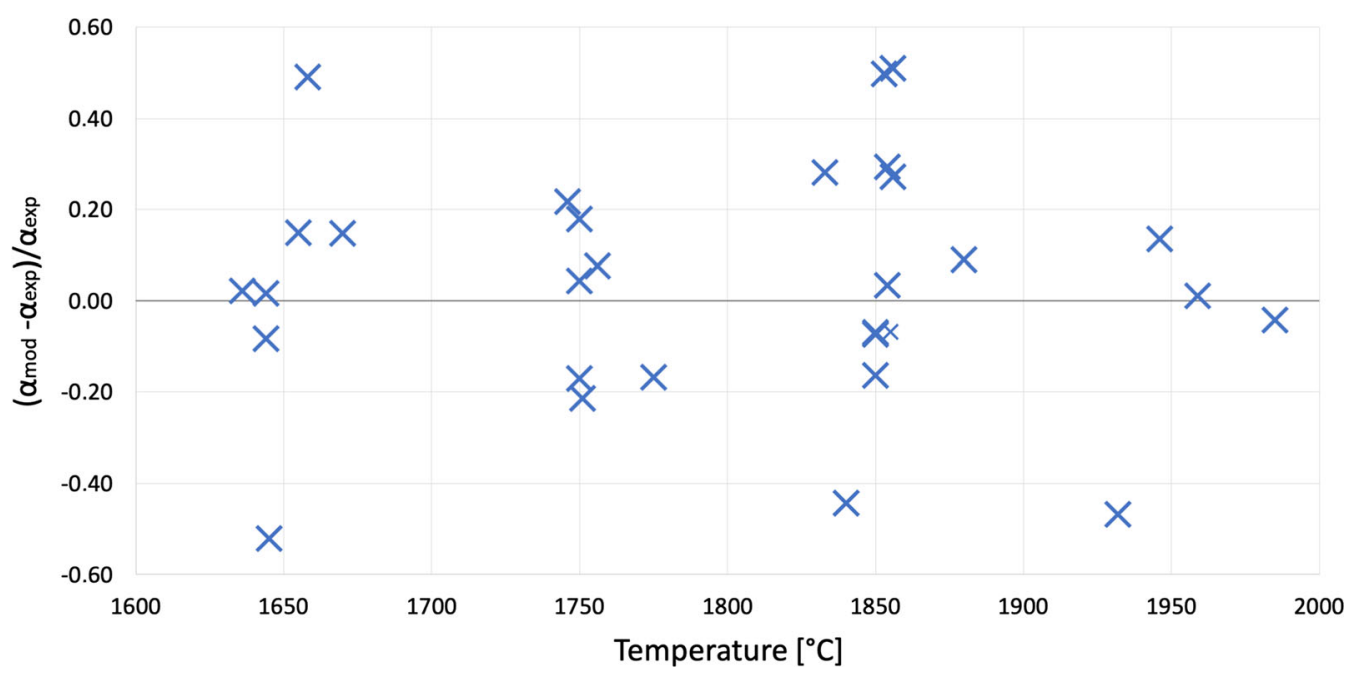

Fig. 8-The difference in modeled and experimental values for degree of reaction, relative to the experimental values, plotted as function of temperature.

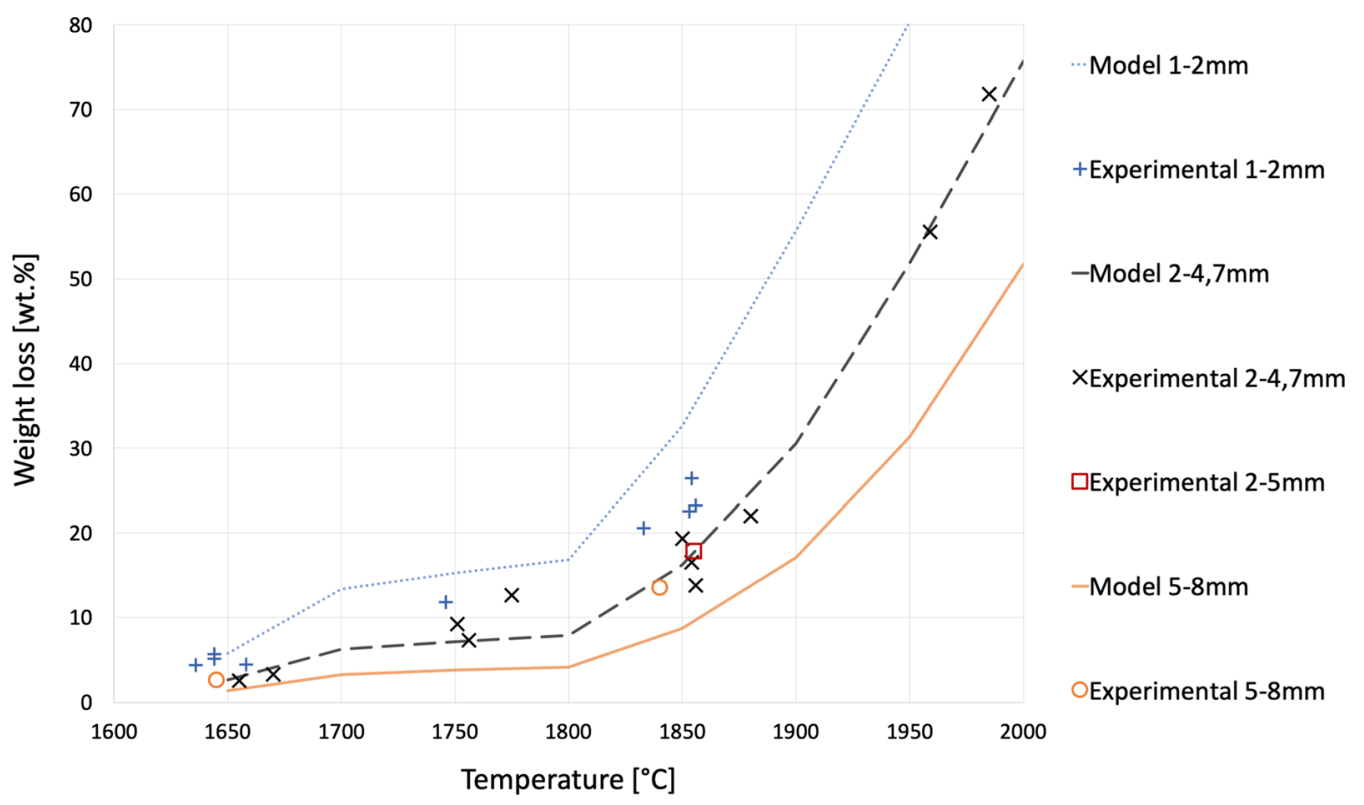

Fig. 9- The weight loss after heating samples to 1650 and $1750{ }^{\circ} \mathrm{C}$ for $120 \mathrm{~min}$ as well as 1850 and $1950{ }^{\circ} \mathrm{C}$ for 60 min. The size fraction of the samples and the modeled value for each fraction at the given time/temperature are additionally included.

The samples agglomerate as the temperature increase, as seen in Figure 7. This is included in the model as an agglomeration factor $(\mathrm{F})$ which is part of the calculation of available reaction area, given by Eqs. [9] through [11]. Note that the agglomeration factor decreases as the degree of agglomeration increases. The degree of agglomeration is a function of temperature, but two constant values are chosen as agglomeration factor, to make the equation for reaction rate as simple as possible. Agglomeration is neglected below the melting point of quartz $(F=1)$ and the value above the melting point is chosen to be the value that give the best fit to experimental data $(F=0.5$, indicating reduction in available reaction area). There is not found any trend in error as function as temperature, as seen in Figure 8, which indicates that the chosen values for agglomeration factor is good. Silicon and silica were mixed before heating in most of the experiments, but some of the experiments with quartz A were performed with silicon layered on top of silica (see Table $\mathrm{V}$ for information on which samples that were mixed). There was no significant difference between the reaction rate of the samples that were mixed and the samples that were layered. The same equation for available reaction area is therefore used for both cases. Section "III-C" elaborates on the difference between layered and mixed samples. 


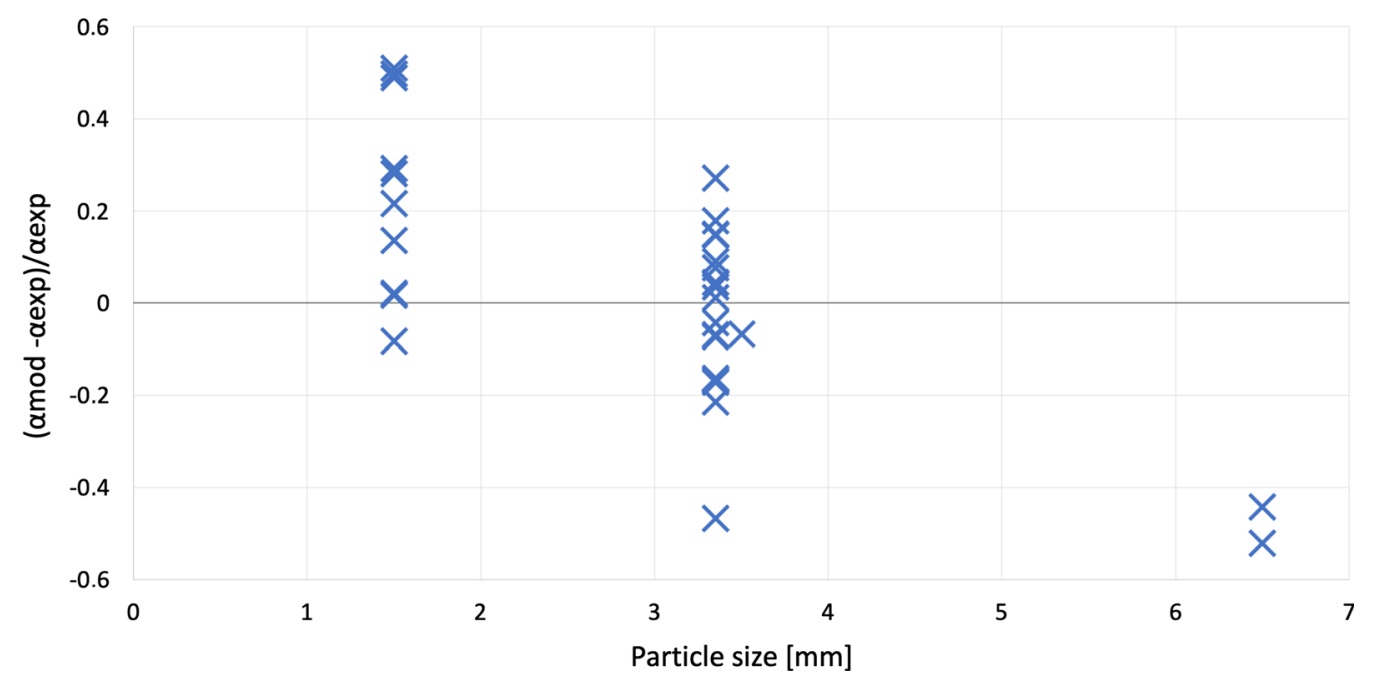

Fig. 10-The difference in modeled and experimental values for degree of reaction, relative to the experimental values, plotted as function of particle size.

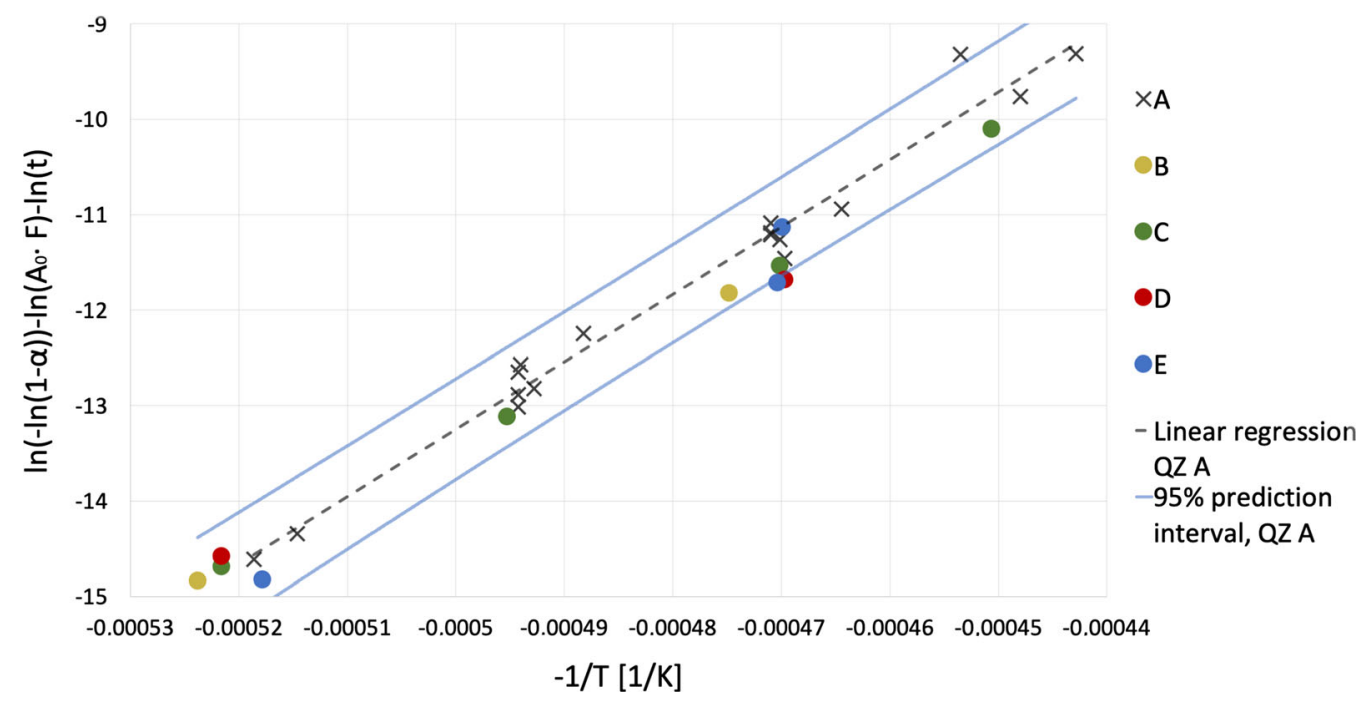

Fig. 11-An Arrhenius plot of all data points (except the two samples of 5 to $8 \mathrm{~mm}$ fraction) with linear regression and intervals based on quartz A only. All types of quartz seem to follow the same model.

$$
\begin{gathered}
\frac{\mathrm{d} \alpha}{\mathrm{d} t}=k_{0} A \exp \left(-\frac{Q}{\mathrm{RT}}\right) \\
A=A_{0, \mathrm{Si}}(1-\alpha) F \\
A_{0, \mathrm{Si}}=\frac{1}{\rho_{\mathrm{Si}}} \frac{S_{\text {part. }}}{V_{\text {part. }}} \\
T<T_{m, \mathrm{QZ}} \Rightarrow F=1 T>T_{m, \mathrm{QZ}} \rightarrow F=0.5
\end{gathered}
$$

The data points from heating at $1650^{\circ} \mathrm{C}$ and $1750{ }^{\circ} \mathrm{C}$ for 120 minutes and at $1850^{\circ} \mathrm{C}$ and $1950^{\circ} \mathrm{C}$ for 60 minutes have been selected and plotted along with a model for these times and temperatures, as shown in Figure 9. The model shows a good fit to the size fraction of 2 to $5 \mathrm{~mm}$, but it predicts too high weight losses for samples of a smaller fraction and too low weight losses for samples of a higher fraction. This can also be seen in Figure 10 where the difference between the modeled and experimental values is plotted as a function of particle size. The trend in error indicates that there is a need for improvement in calculation of available area. Despite this, the model predicts reasonable values, and there is no trend in the error as function of temperature, as seen in Figure 8. This indicates that the value obtained for 
activation energy is reasonable and it can be used for comparison of the different $\mathrm{SiO}$-producing reactions in a silicon furnace.

\section{A. The Reaction Rate of Different Industrial Quartz Samples}

Five different types of quartz have been included in the measurements of silicon/silica reaction rate. The amount of impurities in each quartz sample and their transformation rate vary significantly, but this does not seem to cause any significant difference in reaction rate. Figure 11 shows an Arrhenius plot of all reaction rate data obtained, except the two samples with a high fraction $(5$ to $8 \mathrm{~mm}$ ). The figure includes a 95 pct prediction interval which is only based on data from heating of quartz A (the reference sample). One of the data points from quartz A lay outside the interval and two of the data points from quartz $\mathrm{B}$ to $\mathrm{E}$ lay at the border of the interval. It is therefore concluded that the reaction rate of silicon mixed with different types of quartz can be described by one equation. There is no significant difference between the reaction rate of the five different industrial quartz samples.

\section{B. Formation of SiC at Crucible Interface}

In this work, the weight loss of a silicon and silica mixture is directly correlated to the degree of reaction; weight loss due to other reactions is neglected. A layer of silicon carbide was formed at the crucible interface of each sample, which is assumed to be due to reaction with both silicon and silica. Reaction with silica case would result in formation of $\mathrm{CO}$ gas in addition to $\mathrm{SiO}$ gas and the second case (reaction with silicon) would reduce the amount of silicon available for the $\mathrm{Si}+\mathrm{SiO}_{2}$ reaction. Both cases will affect the correlation between $\mathrm{Si} / \mathrm{SiO}_{2}$ reaction rate and weight loss of a $\mathrm{Si} / \mathrm{SiO}_{2}$ mixture heated in graphite crucibles. The layer thickness was measured at 13 samples and no correlation between the thickness, temperature, and time of the experiment was found. It is therefore assumed that a relatively dense and stable layer is formed after short time at low temperatures. Calculations were performed, to calculate an average weight loss of each sample, due to interaction with the crucible. The calculations were based on the assumption that the $\mathrm{SiC}$ layer is present on the inside of the graphite crucible up to a height of $2 \mathrm{~cm}$, with a depth of $150 \mu \mathrm{m}$ and that it is consisting of $75 \mathrm{vol}$ pet graphite

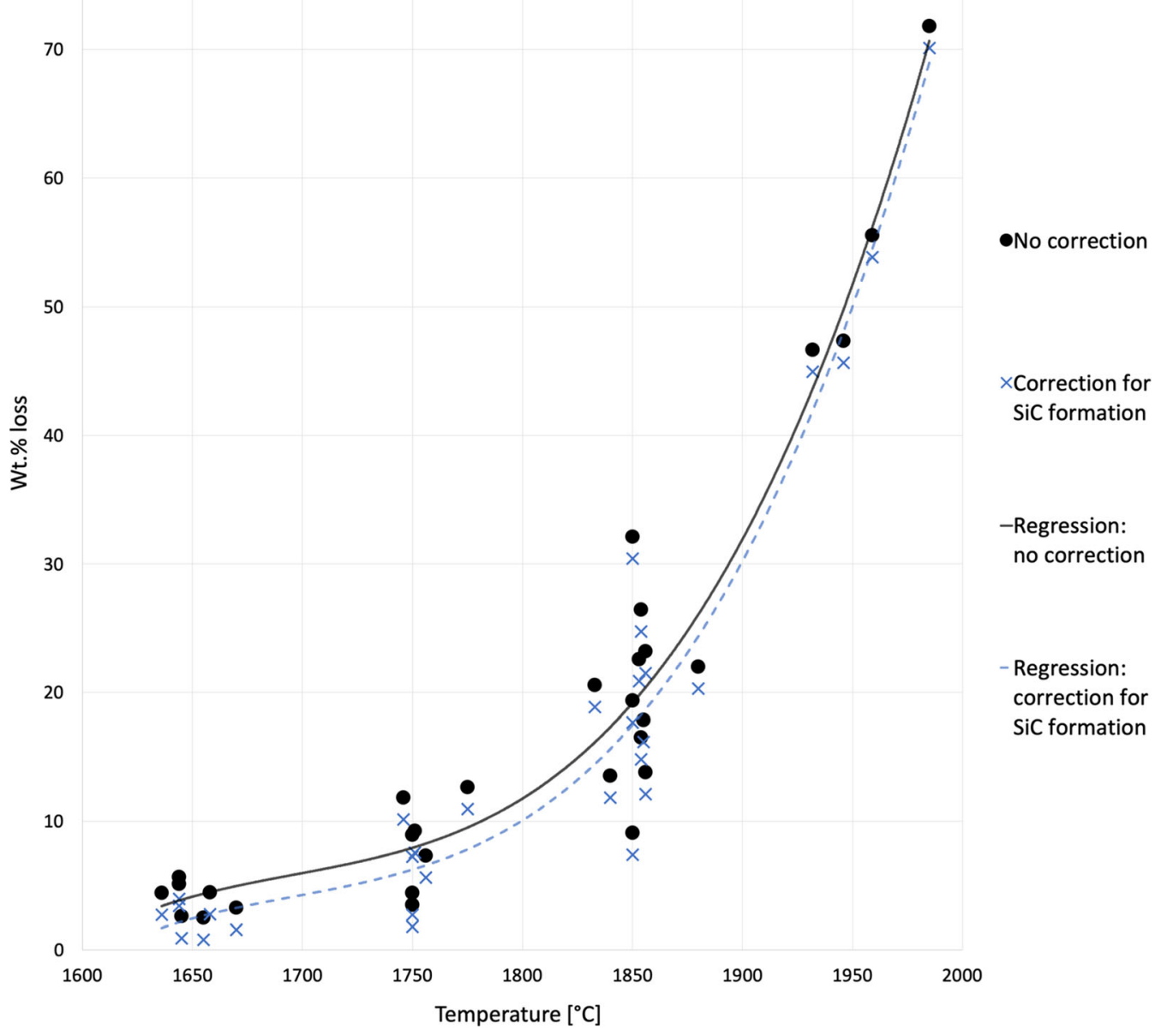

Fig. 12-The degree of reaction for each sample without any correction is plotted and marked with dots, while the degree of reaction with correction for weight loss due to $\mathrm{SiC}$ formation is marked with X's. The corrected value is based on total weight loss minus the weight loss due to interaction with crucible, causing formation of $\mathrm{CO}$ gas. 

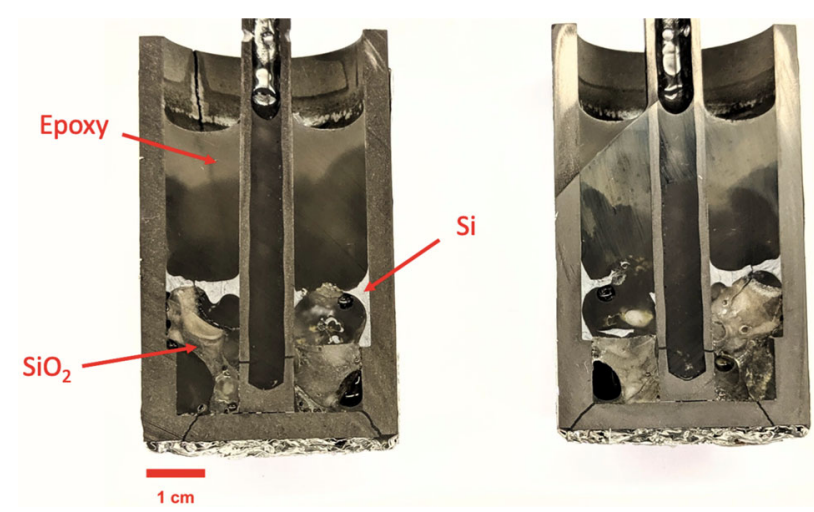

Fig. 13-A sample heated for $60 \mathrm{~min}$ at $1850{ }^{\circ} \mathrm{C}$. Mixed raw materials in a graphite crucible.

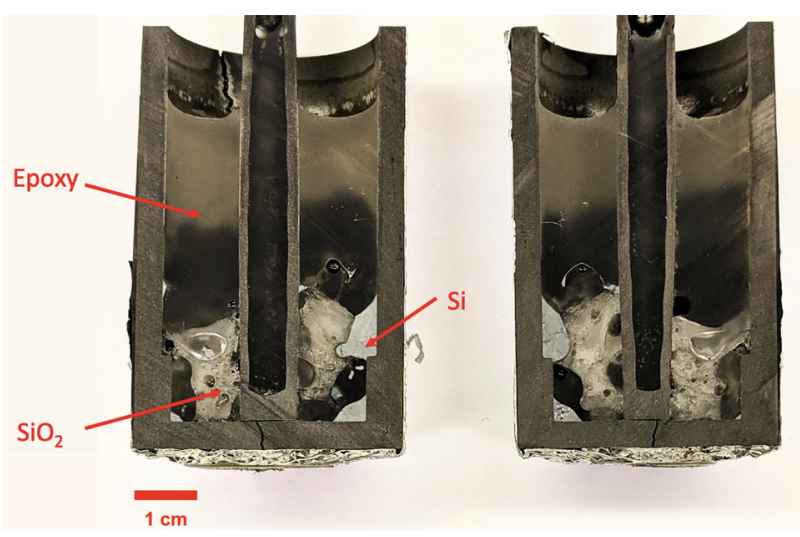

Fig. 14-A sample heated for $60 \mathrm{~min}$ at $1850{ }^{\circ} \mathrm{C}$. Layered raw materials in a graphite crucible.

and 25 vol pet SiC. Furthermore, it is assumed that 50 pct of the $\mathrm{SiC}$ was formed as a result of reaction with silica and the rest due to interaction with silicon. All of those assumptions are based on an average of values obtained by inspection of LOM and SEM images of 13 samples and the assumption that available reaction area is limiting both reactions $\left(\mathrm{Si}+\mathrm{C}\right.$ and $\mathrm{SiO}_{2}+\mathrm{C}$ ). The last assumption is justified by values for Gibbs free energy listed in Table I, showing that both reactions can occur at temperatures above $1600^{\circ} \mathrm{C}$. Analysis of macro images shows that available reaction area is limited and within the same range for $\mathrm{Si}+\mathrm{C}$ and $\mathrm{SiO}_{2}+\mathrm{C}$.

This gave a total weight loss of $1.7 \mathrm{wt}$ pet for each sample due to interaction with crucible, when the total sample weight is $20 \mathrm{~g}$. This is a significant amount for samples heated to low temperatures, where the degree of reaction is low, but it is not significant for samples heated to higher temperatures. A plot of data for degree of reaction with and without a correction for formation of a $\mathrm{SiC}$ layer is included in Figure 12. Interaction with the crucible is still neglected in the entire temperature

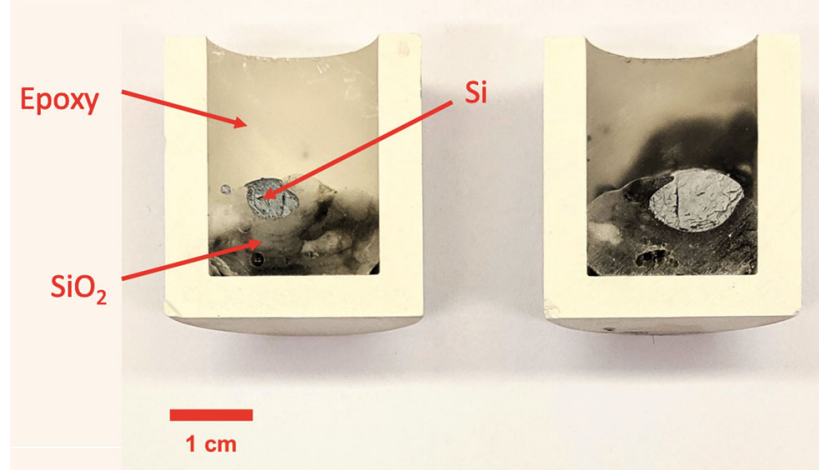

Fig. 15-A sample heated for $60 \mathrm{~min}$ at $1750{ }^{\circ} \mathrm{C}$. Layered raw materials in a h-BN crucible.

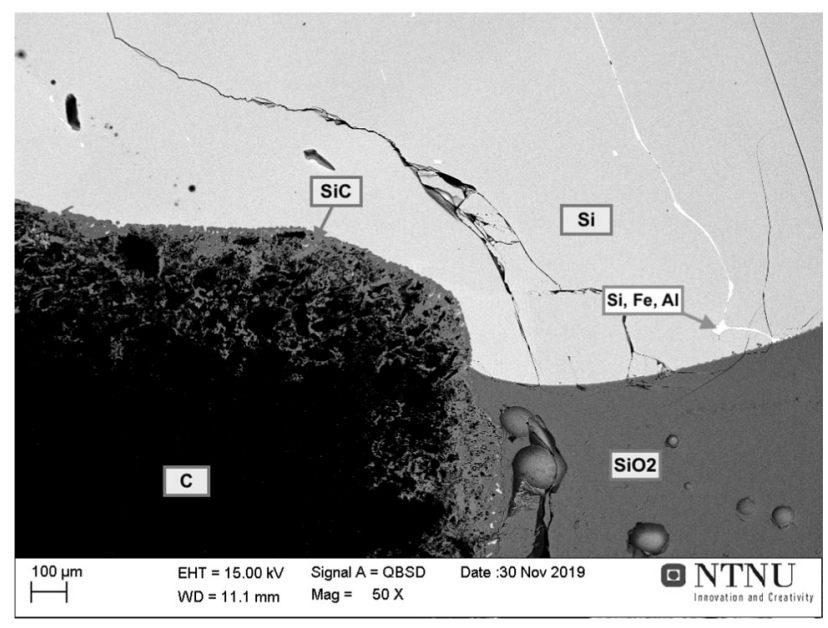

Fig. 16-Image of a sample that was heated for $60 \mathrm{~min}$ at $1850^{\circ} \mathrm{C}$ in a graphite crucible - picture taken with SEM BSE. The image is taken at the crucible interface, at a height where there is a small edge (the edge is not of importance to these experiments but could be used to separate crucible into two chambers). The image shows the expected phases, graphite (C), silicon carbide at the crucible interface, silica, and silicon with impurities at the grain boundaries. An approximate chemical composition at selected spots were obtained by EDS analysis.

range of this model, to make the model as simple as possible, even though it is significant at $1650{ }^{\circ} \mathrm{C}$. This means that the model might predict a reaction rate slightly too high at low temperature and time.

\section{Phase Distribution}

Silicon and silica agglomerate at high temperature as shown in Figure 7. Both layering and mixing of silicon and silica have been performed prior to heating of the samples in a graphite crucible. Macro images of a sample where the raw materials were mixed before heating is shown in Figure 13 and an image from a sample where the raw materials were layered can be seen 


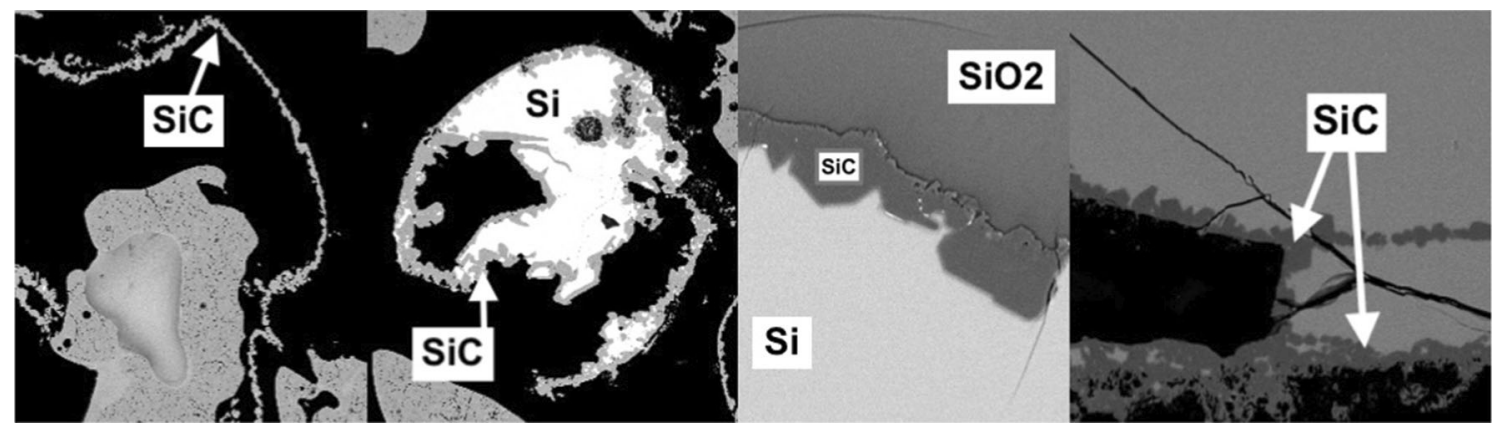

Fig. 17- Silicon carbide on the surface of silicon particles/droplets in samples heated to 1650 and $1750{ }^{\circ} \mathrm{C}$.

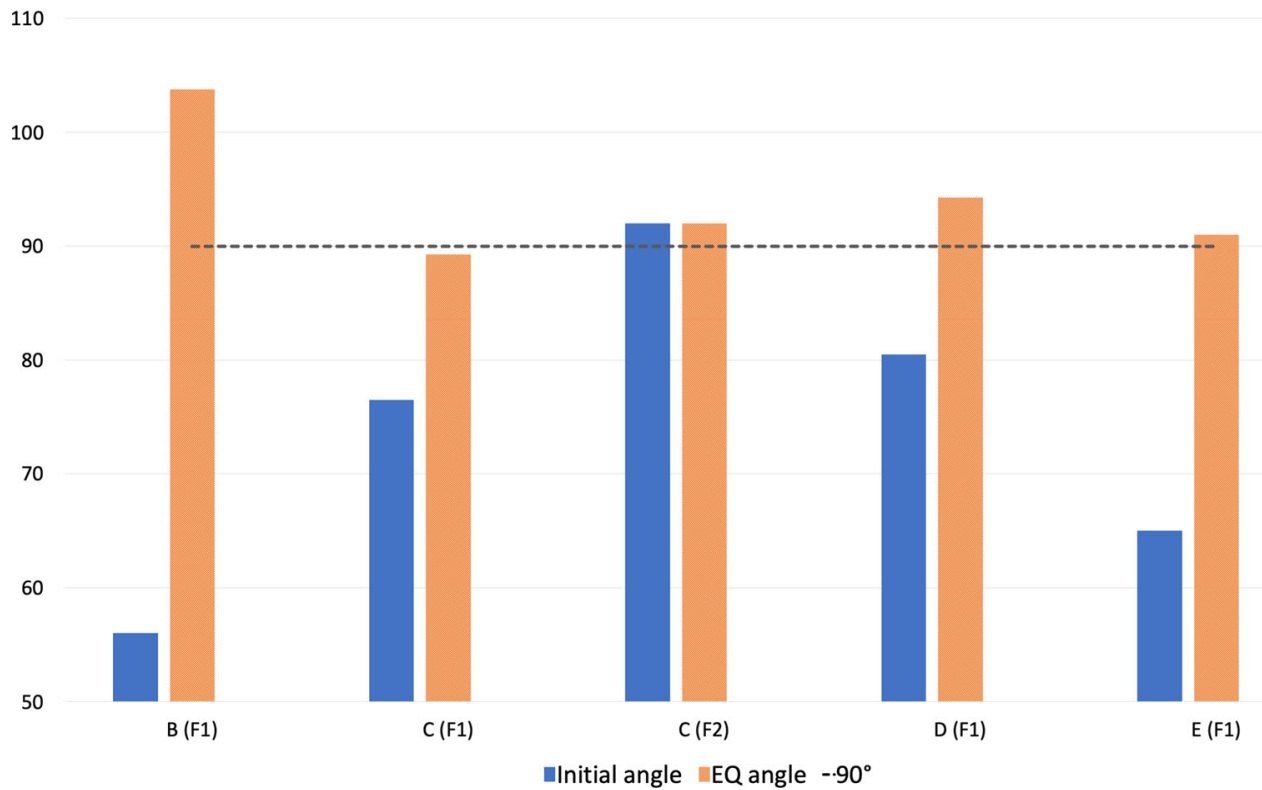

Fig. 18-The figure shows the initial wetting angle, right after complete melting and the equilibrium angle for silicon on substrates of quartz B to E. F1 indicates that furnace 1 was used, and F2 indicated that furnace 2 was used (two similar furnaces).

in Figure 14 (silicon layered on top of silica before heating). Silicon and silica agglomerate in both cases and the silicon tends to stay on top of the silica at temperatures up to $1900{ }^{\circ} \mathrm{C}$, even though the density of silicon is higher than silica. There was not found any significant difference in the available reaction area for samples with layering and mixing of raw materials and whether the raw materials were mixed or layered did not affect the reaction rate significantly. One experiment was performed with heating of silicon and silica in a boron nitride crucible, to investigate the phase distribution after heating in a non-wetting crucible. The silicon did not drain to the bottom of the crucible in this case either, as seen in Figure 15. A high silica viscosity is therefore assumed to prevent the silicon from draining to the bottom of the crucible.

The samples were analyzed by SEM and the expected phases were found: Silicon, silica, graphite, and silicon carbide at the crucible interface, as seen in Figure 16. Furthermore, impurities at the grain boundaries of silicon were found, which is expected, due to a low solubility of impurities in solid silicon. There was only one unexpected finding: Silicon carbide was found on the surface of the silicon heated to $1650{ }^{\circ} \mathrm{C}$ and $1750{ }^{\circ} \mathrm{C}$, as seen in Figure 17; this was not found in samples heated to $1850{ }^{\circ} \mathrm{C}$ and $1950{ }^{\circ} \mathrm{C}$. The reason for this is not fully understood, but an explanation could be that silicon carbide is formed at the surface of the silicon particles/droplets at low temperatures due to presence of small amounts of $\mathrm{CO}_{\mathrm{g}}\left(\Delta \mathrm{G}^{\circ}<0\right.$ for $2 \mathrm{Si}+\mathrm{CO}_{\mathrm{g}}=\mathrm{SiO}_{(g)}$ $+\mathrm{SiC}$ at $\mathrm{T}<1900^{\circ} \mathrm{C}$, according to values in Table I) and that the silicon carbide reacts with silica at higher temperature. This indicates that the silica $/ \mathrm{SiC}$ reaction rate is low at temperatures up to $1750{ }^{\circ} \mathrm{C}$, which is within agreement with work done by Tangstad et al. ${ }^{[3]}$ The silicon carbide reduces the contact and reaction area between silicon and silica but there is still contact between the two phases due to the fact that the SiC layer has a low density. Empty shells of silicon carbide are observed, indicating that all of the silicon inside these 

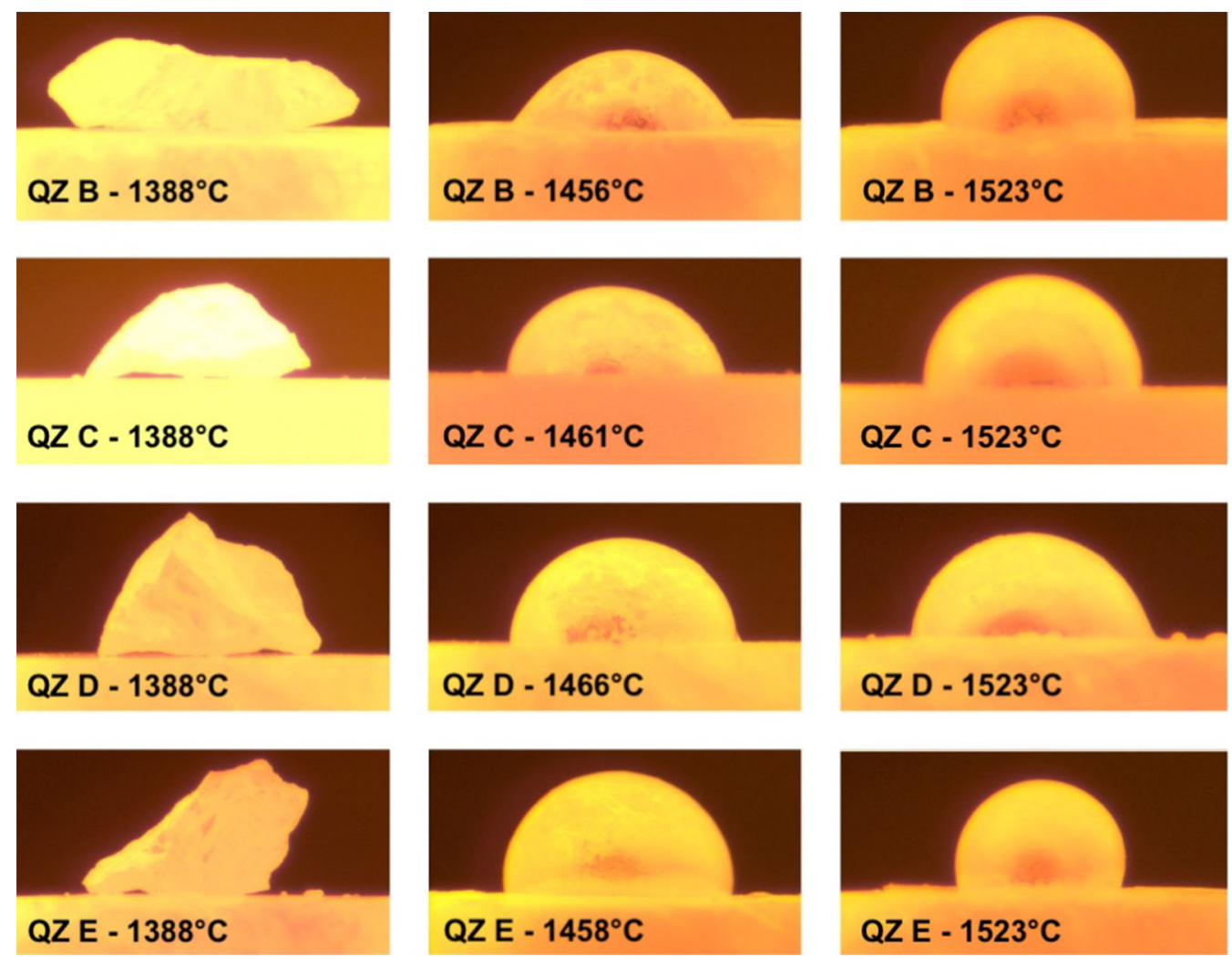

Fig. 19-Images taken during heating of the silicon and silica samples in furnace 1, one image of each quartz sample before the silicon melted (images to the left), one right after complete melting (images in the middle), and one image taken during the isothermal heat treatment at $1523^{\circ} \mathrm{C}$ (images to the right). The type of quartz substrate and the temperature is indicated in each image.

droplets has reacted with silica. It is not known to what degree the silicon carbide layer affects the silicon/silica reaction rate and it is therefore not included in the model.

\section{Properties of the Different Quartz Samples}

Silicon was heated on substrates of quartz B, C, D, and $\mathrm{E}$ in a sessile drop furnace, to investigate the silicon/ quartz wettability. The initial angle was right below $90^{\circ}$ for all, except for one parallel of sample $\mathrm{C}$ which was measured in a different, but similar furnace. The formation of bubbles at the silicon/silica interface starts right after melting of the silicon, which is assumed to be formation of $\mathrm{SiO}$ gas. The wetting angle starts to increase at the same time, up to 89 to $94 \mathrm{deg}$ for all samples except for quartz B which increases to $104^{\circ} \mathrm{C}$. The wetting angle increases for a few minutes and reaches an equilibrium before the isothermal temperature of $1523^{\circ} \mathrm{C}$ is reached. The equilibrium angle is reached a short time after melting and is therefore assumed to be the angle of importance, both in the experiments performed in this work and for behavior in an industrial furnace. The wetting angle oscillates with a few degrees at equilibrium, most likely due to gas formation at the silicon/silica interface, but it is kept above $90{ }^{\circ} \mathrm{C}$ for all samples (except one parallel of quartz $\mathrm{C}$ that oscillated around $89^{\circ} \mathrm{C}$ ). It is therefore concluded that silicon does not wet either of the industrial quartz samples and the wetting angle ranges from 90 to $95^{\circ} \mathrm{C}$, except quartz $\mathrm{B}$ who has a wetting angle in the range of 100 to $110^{\circ} \mathrm{C}$, as shown in Figure 18. Images of the samples before melting, right after melting and at equilibrium, can be found in Figure 19. It should be noted that quartz B is the sample with the lowest impurity content. Literature reports a wetting angle between silicon and pure silica of $90^{\circ} \mathrm{C}$ to $95^{\circ} \mathrm{C}$, which is coherent with the measured wetting angle for silicon on substrates of quartz $\mathrm{C}$ to $\mathrm{E}$.

All of the quartz samples (A to E) were heated to $1650{ }^{\circ} \mathrm{C}$ in alumina crucibles and held for 120 minutes before being cooled and analyzed by XRD, to investigate the phase distribution in each sample. There was no significant difference between the phase composition of the samples after heating, except quartz E which had a higher amount of amorphous phase. All types of quartz will transform to cristobalite at $1650{ }^{\circ} \mathrm{C}$ after enough time. It seems like the chosen holding time of 120 minutes (corresponding to the holding time used for silicon/silica samples heated to $1650{ }^{\circ} \mathrm{C}$ ) is long enough for all the samples to approach equilibrium phase composition. However, as stated by Jusnes, there is a significant difference in transformation rate of quartz B, 


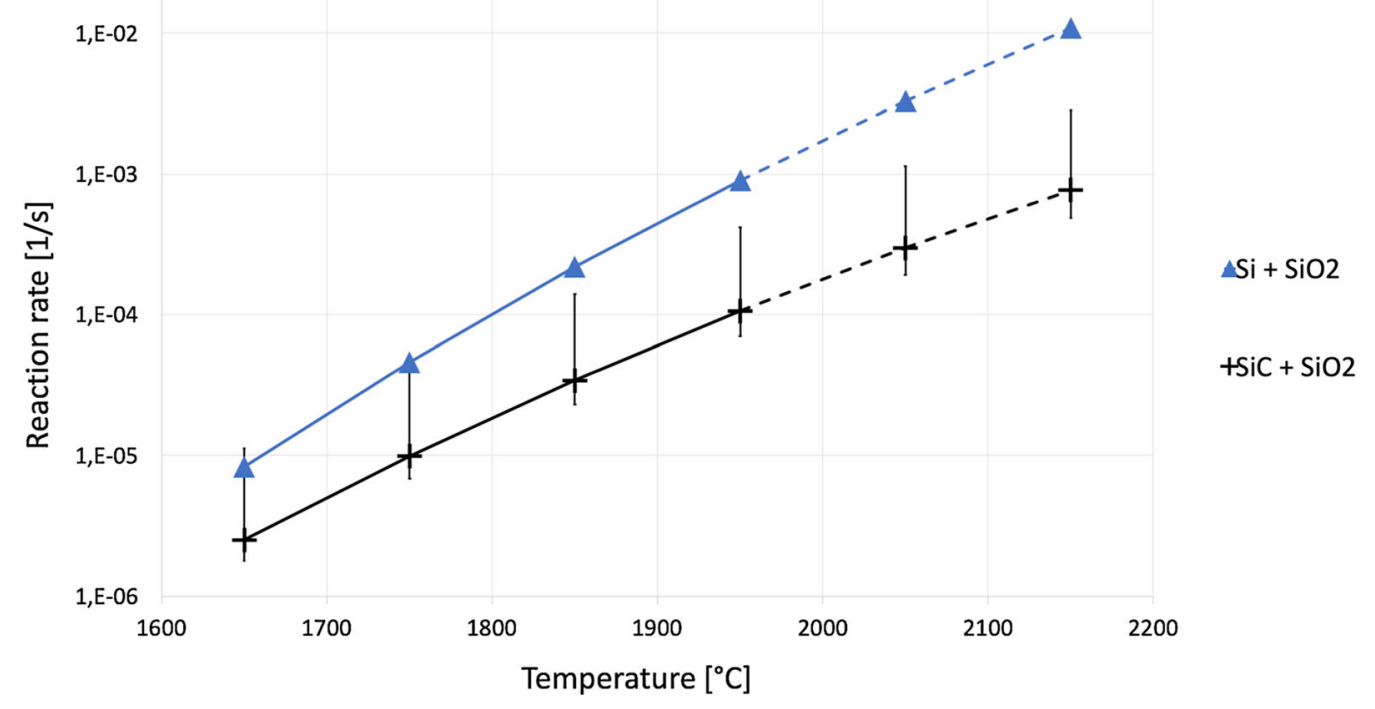

Fig. 20-The reaction rate of the two SiO-producing reactions in a silicon furnace for a given reaction area on a logarithmic scale. The reaction area (A) is set to be determined by 1 to $2 \mathrm{~mm}$ silicon particles for the silicon/silica reaction and 1 to $2 \mathrm{~mm}$ silica particles for the silica/SiC reaction (marked by crosses). The reaction rate for $\mathrm{SiO}_{2}+\mathrm{SiC}$ was obtained from a model developed by Tangstad et al. (marked by triangles). ${ }^{[3]}$ The reaction rate for $\mathrm{SiO}_{2} / \mathrm{Si}$ was obtained by the model developed in this thesis. The dotted line is outside the temperature range of the models.

$\mathrm{C}$, and $\mathrm{D}$ (the work does not include quartz $\mathrm{A}$ and $\mathrm{E}){ }^{[9]}$ Hence, it can be concluded that the transformation rate does not affect the $\mathrm{SiO}$ formation of the silicon/silica mixtures in this report. This could be due to the fact that most of the samples were heated at higher temperatures when silicon/silica reaction rate was measured, at temperatures where all of the samples will be transformed into cristobalite and start melting before the isothermal temperature is reached.

The work done by Jusnes et al. shows that there is a significant difference in decrepitation of quartz B, C, and $\mathrm{D}$ after shock heating. ${ }^{[12]}$ Decrepitation after shock heating does not seem to affect reaction rate of silicon and silica mixtures, because the samples have a difference in decrepitation but no difference was found in their reaction rate. The samples were heated at a rate of $50{ }^{\circ} \mathrm{C} / \mathrm{min}$ in the experiments where the reaction rate was measured, and one can assume that decrepitation might affect reaction rate of a mixture if the samples are shock heated. The surface of silicon is lower than the surface of silica in the experiments where weight loss of a 1:1 molar mixture is measured, due to a density difference. Any agglomeration of the silicon and decrepitation of the quartz would further reduce the surface area of silicon relative to the silica. This verifies that the surface area of silicon is the limiting factor when it comes to available reaction area, and it is a good assumption for available reaction area, as used in this reaction model, $A_{0, \text { model }}=A_{0, \mathrm{Si}}$.

There is a significant difference in the melting rate of quartz B and C but no information has been obtained for the other samples. The melting rate of each quartz sample is however assumed to be quite different in the present experiments, due to a large difference observed between quartz B, C, and other industrial samples. ${ }^{[11]}$ As this has not affected the reaction rate between silicon and silica, this verifies that the overall reaction rate is independent on the melting rate. It should however be noted that the experiments have been performed at $1650{ }^{\circ} \mathrm{C}, 1750{ }^{\circ} \mathrm{C}, 1850{ }^{\circ} \mathrm{C}$, and $1950{ }^{\circ} \mathrm{C}$, at relatively large temperature intervals and there might be a local variation in reaction rate due to a difference in melting rate.

There is a significant difference in content of impurities, decrepitation after shock heating, and rate of phase transformation between the different types of quartz, but no significant difference in reaction rate. Therefore, it is assumed that impurities, decrepitation after shock heating, and phase transformation rate have an insignificant impact on the reaction rate of silicon and silica mixtures when heated at a rate of $19{ }^{\circ} \mathrm{C} / \mathrm{min}$. There is a significant difference in melting rate of each sample and it is assumed to not affect the overall reaction rate, but there could be local differences between the different quartz samples in the temperature range where the samples soften and melt.

\section{E. Comparison of the Two SiO-Producing Reactions in a Silicon Furnace}

Figure 20 shows the reaction rate of both SiO-producing reactions on a logarithmic scale, in a temperature range from 1650 to $2150{ }^{\circ} \mathrm{C}$. The figure is based on an initial reaction rate for the $\mathrm{Si} / \mathrm{SiO}_{2}$ and $\mathrm{SiC} / \mathrm{SiO}_{2}$ reaction described by Eqs. [8] through [5], respectively. The initial reaction area $\left(A_{0}\right)$ is set to be $17.4 \mathrm{~cm}^{2} \mathrm{~g}_{\mathrm{Si}}^{-1}$ for the silica/silicon reaction and $15.1 \mathrm{~cm}^{2} \mathrm{~g}_{\mathrm{SiO}_{2}}^{-1}$ for the silica/SiC reaction. This is based on calculation of available reaction area for the two reactions, where 1 to $2 \mathrm{~mm}$ particles of silicon limit the reaction rate of $\mathrm{Si} /$ $\mathrm{SiO}_{2}$ and 1 to $2 \mathrm{~mm}$ particles of $\mathrm{SiO}_{2}$ limit the reaction rate of $\mathrm{SiO}_{2} / \mathrm{SiC}$. The calculation of initial reaction area is described by Eq. [10] for the silicon/silica reaction and the same calculations have been performed for the silica/ 
silicon carbide reaction, where the density of silicon was replaced by density of silica. The black line in Figure 20 represents the reaction rate of silicon and silicon carbide based on the average activation energy and the error bars indicate rate based on maximum and minimum values reported by Tangstad et al. ${ }^{[3]}$

There is a difference between the reaction rate of the two reactions in this case, as seen in Figure 20. The difference is small at low temperatures, but significant at higher temperatures. Therefore, it could be argued that there is a significant difference between the rate of each reaction at elevated temperatures for the given available reaction area, but the reaction rate of both reactions is highly dependent on the available reaction area. The available reaction area could vary significantly for the two $\mathrm{SiO}$-producing reactions within a furnace. This leads to the conclusion that the production of $\mathrm{SiO}$ gas in a silicon furnace is highly dependent on the available reaction area for the two possible reactions.

\section{CONCLUSION}

The reaction rate of a silicon and silica mixture increases with time and temperature and can be described by Eq. [12] for various types of industrial quartz. The reaction $\mathrm{Si}+\mathrm{SiO}_{2}$ has a reaction constant $\left(k_{0}\right)$ equal to $6.25 \times 10^{8} \mathrm{~g} \mathrm{~s}^{-1} \mathrm{~m}^{2}$ and an activation energy $(Q)$ equal to $557 \mathrm{~kJ} \mathrm{~mol}^{-1}$. Impurities, decrepitation after shock heating, melting rate, and phase transformation rate are silica properties that have an insignificant impact on the reaction rate of silicon and silica mixtures when heated at a rate of $50{ }^{\circ} \mathrm{C} / \mathrm{min}$.

$$
\frac{\mathrm{d} \alpha}{\mathrm{d} t}=6.25 \times 10^{8} A \exp \left(-\frac{55710^{3}}{\mathrm{RT}}\right) .
$$

The reaction rate of the two $\mathrm{SiO}$-producing reactions in a silicon furnace $\left(\mathrm{Si}+\mathrm{SiO}_{2}\right.$ and $\left.\mathrm{SiO}_{2}+\mathrm{SiC}\right)$ is within the same range as long as their available reaction area is within the same range. The reaction rate of both reactions increases significantly with temperature and so does their available reaction area as you go deeper in a silicon furnace. This means that whether reaction with silicon or silicon carbide contributes the most towards formation of $\mathrm{SiO}$ gas in a silicon furnace is determined by the phase distribution in the hot-temperature zone.

The calculation of available reaction area is one weakness of this model. There is a trend in the difference between experimental data and modeled data as a function of particle size. This indicates that the expression for available reaction area could be improved. The reaction rate of silicon and silica is shown to increase with time and temperature, but work done by Andersen indicates that there might be a local reduction of rate around the melting point of silica. ${ }^{[5]}$ Whether there is a local drop or not could be verified by a few experiments at temperatures ranging from 1700 to $1750{ }^{\circ} \mathrm{C}$. Despite that, the model is considered to predict reasonable values for reaction rate of a silicon and silica mixture in the range from 1650 to $1950{ }^{\circ} \mathrm{C}$.

\section{ACKNOWLEDGMENTS}

The Norwegian Ferroalloy Research Association (FFF) and the Norwegian Research Council (NRC) are appreciated for their financial support through the KBN project Controlled Tapping, Project No. 267621 and IPN project HighTempQuartz, Project No. 256788 .

\section{FUNDING}

Open access funding provided by NTNU Norwegian University of Science and Technology (incl St. Olavs Hospital - Trondheim University Hospital).

Open Access This article is licensed under a Creative Commons Attribution 4.0 International License, which permits use, sharing, adaptation, distribution and reproduction in any medium or format, as long as you give appropriate credit to the original author(s) and the source, provide a link to the Creative Commons licence, and indicate if changes were made. The images or other third party material in this article are included in the article's Creative Commons licence, unless indicated otherwise in a credit line to the material. If material is not included in the article's Creative Commons licence and your intended use is not permitted by statutory regulation or exceeds the permitted use, you will need to obtain permission directly from the copyright holder. To view a copy of this licence, visit http://creativecommons. org/licenses/by/4.0/.

\section{REFERENCES}

1. A. Schei, J.K. Tuset, and H. Tveit: Production of High Silicon Alloys, Tapir, Trondheim, 1998.

2. F. Li and M. Tangstad: Metall. Trans. B, 2017, vol. 48, p. 853.

3. M. Tangstad, J. Safarian, S. Bao, E. Ringdalen, and A. Valderhaug: Aspects Min. Miner. Sci., 2019, vol. 3, p. 2.

4. S. Bao, M. Tangstad, K. Tang, E. Ringdalen, The thirteenth International Ferroalloys Congress - Efficient technologies in ferroalloy industry 273-282 (2013).

5. V. Andersen, Condensate formation in the silicon process. Master's thesis, Norwegian University of Science and Technology (2011).

6. C. Klein and C.S. Hurlbut: Manual of Mineralogy, 21 th ed., Wiley, New York, 1993.

7. G. Blackman: Si Chemical Data, 7th ed., Wiley, New York, 2014.

8. S.J. Stevens, R.J. Hand, and J.H. Sharp: J. Mater. Sci., 1997, vol. 32, p. 2929

9. K. Jusnes, Phase transformations and thermal degradation in industrial quartz. Ph.D. thesis, Norwegian University of Science and Technology (2020).

10. M.E. Kjelstadli, Kinetics and mechanism of phase transformations from quartz to cristobalite. Master's thesis, Norwegian University of Science and Technology (2016).

11. E. Nordnes, Softening and melting properties of quartz. Master's thesis, Norwegian University of Science and Technology (2019).

12. K.F. Jusnes, M. Tangstad, E. Ringdalen, in Infacon XV: International Ferro-Alloys Congress, Cape Town, South Africa, ed. by R. Jones, P. den Hoed (2018).

13. A. Ciftja, T.A. Engh, and M. Tangstad: Metall. Trans. B, 2010, vol. 41, pp. 3183-95.

14. O. Dezellus, S. Jacques, F. Hodaj, and N. Eustathopoulos: $J$. Mater. Sci., 2005, vol. 40, pp. 2307-11. 
15. L.D. Alphei, R. Grotjahn, V. Becker, R. Janhsen, M. Douvidzon, and J.A. Becker: J. Mater. Sci., 2013, vol. 48, p. 7350

16. H. Kanai, S. Sugihara, H. Yamaguchi, T. Uchimaru, N. Obata, T. Kikuchi, F. Kimura, and M. Ichinokura: J. Mater. Sci., 2007, vol. 42 , p. 9529.

17. H. Fujii, M. Yamamoto, S. Hara, and K. Nogi: J. Mater. Sci., 1999, vol. 34, p. 3165.

18. J. Vangskåsen, Condensate formation in the silicon process. Master's thesis, Norwegian University of Science and Technology (2011).
19. B. Drevet, R. Voytovych, R. Israel, and N. Eustathopoulos: $J$. Eur. Ceram. Soc., 2009, vol. 29, p. 2263.

20. Z. Yuan, W.L. Huang, and K. Mukai: Appl. Phys. A, 2004, vol. 78 , p. 617.

21. J.A. Champion, B.J. keene, and S. Allen: J. Mater. Sci., 1973, vol. 8, p. 423.

Publisher's Note Springer Nature remains neutral with regard to jurisdictional claims in published maps and institutional affiliations. 